\title{
Driving a Hard Bargain is a Balancing Act: How social preferences constrain the negotiation
} process.

\author{
Yola Engler Lionel Page*
}

\begin{abstract}
We investigate the effect of opening offers in bargaining. Using an experimental bargaining game, we find that a first offer has a significant impact on the bargaining outcome even if it is costless to reject. First offers convey information on the player's reservation value induced by his social preferences and they are most often accepted when they are not above the equal split. However, offers which request much more than the equal split induce punishing counter-offers triggered by the responder's social preferences. The bargaining outcome is therefore critically influenced by the balance of toughness and kindness signalled through the offers made in the haggling phase.
\end{abstract}

JEL classification: C70; C91;D63; D64

*We thank James Cox, Nick Feltovich, Martin Kocher, Ariel Rubinstein, Tom Wilkening, Erte Xiao and Daniel Zizzo as well as participants from the ANZWEE and the Econometrics Society Summer School for their comments. Engler and Page: School of Economics and Finance, Queensland University of Technology and QuBE (e-mail: yola.engler@qut.edu.au and lionel.page@qut.edu.au). 
The usual haggling process is based on imperfect information, the hagglers trying to propagandize each other into misconceptions of the utilities involved. Nash (1953), Two-person cooperative games

Lest readers think erroneously that it's always wise to bargain tough. Raiffa (1982), The Art and Science of Negotiation

\section{Introduction}

Bargaining is pervading in economic and social interactions and it has been a natural object of study for economists. The large economic literature on economic bargaining has brought many insights about how bargaining outcomes are determined depending on the bargaining power, exit options and preferences of the bargainers. Still, little is known about the negotiation process itself: what is a good opening offer, how long should you stick to an offer and how much should you change your offer when it is a deadlock? Negotiations in real economic situations often seems an art which requires expert practice to excel. They are typically characterised by imperfect information and use of messages which are hard to measure and quantify. As a consequence, studying the negotiation process in the field is challenging.

This paper investigates a critical aspect of negotiations: the "haggling" process where players exchange offers which are costless to reject. We focus here on the effect of first offers. To do so, we design a bargaining game where the zone of possible agreements is known (similarly to an ultimatum game). Under standard assumptions of common knowledge of rationality and payoff-maximization, first offers should not influence the final outcome. However, the fact that bargainers may have social preferences implies that it is actually a game of imperfect information where players' preferences are not common knowledge. Players can use the haggling process to try to influence each others' beliefs about their personal preferences (Nash, 1953). To assess the effect of first offers on the bargaining process, we study the effect of a wide range of first offers on the reaction of the player receiving it. We elicit both the actions of the receiver and his first and second order beliefs. This design allows us to study whether and how the level of the 
opening offer influences bargainers' beliefs, their actions and the final bargaining outcome.

This study contributes to several important strands of literature. First, it extends the literature on the role of social preferences in bargaining. A large body of work has shown that social preferences limit the range of acceptable outcomes. Bargaining experiments have shown that bargaining outcomes are influenced by players' preferences over payoff distributions (Camerer, 2003); and by their preferences over the intentions of other players (Blount, 1995; Offerman, 2002). Here we show that they also constrain the negotiation process itself. Social preferences can play a role during the sequence of offers and counter-offers in a negotiation. Intention-based preferences influence the bargaining process because offers can be perceived as signalling something about the other player's intentions. As a consequence, the history of offers can influence the final outcome of the bargaining process.

Second, this paper adds to the literature on bargaining with reputation where a player has the possibility to build a reputation for stubbornness by sending an initial message to the other player (Abreu and Gul, 2000; Wolitzky, 2012; Embrey, Fréchette and Lehrer, 2014). Opening offers in real world negotiations are often intended to signal the toughness of ones' bargaining strategy. Yet, little is known about whether the first offer has indeed an impact on the other bargainer's beliefs. ${ }^{1}$ We elicit the belief of the player receiving the first offer (Responder) about the minimal amount the player making the offer (Proposer) would accept. Doing so we can measure whether first offers convey some information about the player's final bargaining stance.

Third, our study complements the research on the role of communication in bargaining games. Experimental studies have found that "cheap talk" phases before the bargaining itself influence players' strategies and therefore the bargaining outcome (Croson, Boles and Murnighan, 2003; Rankin, 2003; Anbarci, Feltovich and Gürdal, 2015). Moreover, offers themselves can be used to communicate feelings and intentions to the other player (Xiao and Houser, 2005). In the context of

\footnotetext{
${ }^{1}$ An interesting related study by Goldreich and Pomorski (2011) looked at the effect of the decision to initiate the bargaining process by making a first offer. In our case, the initiating role is pre-assigned and we study the effect of the level of the first offer.
} 
our lab experiment we isolate and study a simple and precise piece of information: the level of an opening offer which is costless to reject. Such an offer does not formally affect the bargaining power of the player making the offer. However it can have an effect on the bargaining process if it has a role as a communication tool.

Our results are striking in what they reveal about the bargaining process. We find that the first offer has a substantial effect on the bargaining outcome even though it is costless to reject. Proposers' first offers are correlated with their minimum acceptable amounts and therefore carry some information about the Proposer's likely refusal of unfavourable splits. We also find that Proposers are credibly obstinate as they tend to reject unfavourable counter-offers with a high probability. In the end, Proposers are able to get a high proportion of the pie to be divided even though, under standard assumptions, they have as much bargaining power as in the ultimatum game (none).

We also find evidence that the Responder's intention-based social preferences are triggered by first offers. Offers which favour the Proposer are not only rejected but often lead to low counter-offers from the Responder. In a substantial number of cases, the Responder chooses a "punishing" counter-offer which is lower than what he believes is the Proposer's minimum acceptable amount. We are able to investigate different theoretical explanations for such a behaviour. We find that the players' first and second order beliefs do not seem to drive players' behaviour as suggested by psychological game theoretic models of reciprocity (Rabin, 1993; Dufwenberg and Kirchsteiger, 2004). The Responder's reaction to the Proposer's offers appears, instead, compatible with the Levine model of reciprocity and spitefulness where agents care about the type of the other player (Levine, 1998). We also find evidence suggesting that players react negatively to offers which can be perceived as disrespectful as suggested by Yamagishi et al. (2012). This last result is in line with recent research pointing to individual preferences for self-esteem (Bénabou and Tirole, 2006; Ellingsen and Johannesson, 2008), and the demand for respect and status in social interactions (Eriksson and Villeval, 2012; Besley and Ghatak, 2008; Heffetz and Frank, 2008; Charness, Masclet and Villeval, 2010).

The remainder of the paper is organized as follows: The next section inserts our research in the context of the existing literature. Section 3 introduces our 
experimental design and outlines our research hypotheses. It is followed by the analysis of our data and the obtained results in Section 4. Section 5 concludes with a short summary and discussion of our findings.

\section{Related Literature}

Bargaining experiments have found systematic departures from game-theoretic predictions. In the case of alternating bargaining games (Ståhl, 1972; Rubinstein, 1982), the subgame-perfect Nash equilibrium predicts, for similarly impatient and purely self-interested bargainers who have complete information, an immediate agreement on a bigger share for the party that makes the initial offer. However, the evidence from bargaining experiments is that participants do not seem to play rationally in order to maximise their own payoff. The literature in behavioural game theory has therefore suggested that bargainers may have some behavioural types whose strategies differ from standard assumptions.

In particular, the experimental evidence shows that bargainers care about the "fairness" of the bargaining outcome (Roth, 1995). The robustness of this evidence has contributed to motivate models of social preferences where players care about others' payoffs and how these compare to their own payoff (e.g. Fehr and Schmidt, 1999; Bolton and Ockenfels, 2000; Charness and Rabin, 2002).

It has also been suggested that players care about each other's intentions and that they react to the perceived "kindness" of other players. Blount (1995) and Offerman (2002) showed that when the first mover's "action" is determined by a random device, responders are less likely to reject smaller offers than when the offer is made intentionally by the first mover. More evidence for the importance of intentions on rejections can be found in Falk, Fehr and Fischbacher (2003). They show that a $(8 ; 2)$ split in favour of the proposer is more likely to be accepted if the only other alternative was even more unfair $(10 ; 0)$ than if the only other alternative was equitable $(5 ; 5)$.

Models of intention-based preferences have been developed to rationalise these observations. First, in the framework of psychological game theory, Rabin (1993) and Dufwenberg and Kirchsteiger (2004) have proposed models of reciprocal preferences where players deduce the other players' kindness from their beliefs about 
the other players' intended actions. In such a framework, player A will respond kindly to a move from player B when A perceives that B made this move with the belief that it would lead to a good (in some sense) outcome for player A. Second, another influential model by Levine (1998) assume that people react to the type of the other player. An altruist player may want to act altruistically with other altruists but spitefully with other players who are not altruists. Finally, rejections of low offers in the ultimatum game have also been explained by a concern for respect. Rejections can be driven by "wounded pride" (Straub and Murnighan, 1995): disadvantageous offers are seen as signaling a lack of respect on part of the other player. This explanation has received support from the observation that the rejection decisions in the ultimatum game are not correlated with reciprocal attitudes in other distributive games (Yamagishi et al., 2012). Such a behaviour could be driven by a concern for maintaining a reputation as a tough bargainer, which could have been selected by evolution (Burnham, 2007; Embrey, Fréchette and Lehrer, 2014).

If bargainers have different types, it potentially increases the importance of communication in order to find an agreement in a negotiation. Bargainers may want to communicate their true type or lie about it. Indeed, real-world bargaining situations typically include some form of communication which contains declarations about desired outcomes and reservation values. Such statements are not verifiable. Therefore, from a non-cooperative game-theoretic point of view with self-centred bargainers, this communication is "cheap talk" (Crawford and Sobel, 1982). It should not be expected to impact the final outcome of the bargaining process. $^{2}$ However empirical evidence shows that cheap talk in bargaining games can have an effect on the outcomes by influencing players' beliefs (Croson, Boles and Murnighan, 2003; Rankin, 2003; Tingley and Walter, 2011; Kriss, Nagel and Weber, 2013; Anbarci, Feltovich and Gürdal, 2015). ${ }^{3}$ Players' claims in pre-play communication seem to be interpreted as if they contain an element of truth.

\footnotetext{
${ }^{2}$ This is the case because communication has no direct payoff implications. Players with competing interests, as in a bargaining process, have no incentive to communicate truthfully.

${ }^{3}$ Early experimental studies with unstructured bargaining designs already indicated that free communication between bargainers plays a role. In particular, face-to-face bargaining has been found to improve the likelihood of a bargaining agreement, possibly because it provides a richer array of channels of communication "including tone of voice, body language and facial expression" (Roth, 1995, p. 296).
} 
Communication between bargainers is not necessarily restricted to explicit messages. For instance, the rejection of an offer seems to be used to convey a message of dissatisfaction. Studies have found that allowing players to communicate with messages reduces the proportion of rejections (Xiao and Houser, 2005; Andersson et al., 2010). When the dissatisfaction can be either attenuated or expressed by explicit communication between players, the rejection of an offer loses of its appeal. Its role as a signal is mitigated or even redundant.

It is reasonable to think that offers themselves can be used to communicate intent and/or emotion to the other player. Models of bargaining with reputation (Abreu and Gul, 2000; Wolitzky, 2012) show that an initial claim can have an effect if the population contains bargainers with "obstinate" behavioural types who refuse low offers. Embrey, Fréchette and Lehrer (2014) tested experimentally the predictions of the Abreu and Gul (2000)'s model using computer players to generate players credibly obstinate. Their results mostly support the predictions of the model with one notable difference: they observe more conflict in their bargaining game than predicted by the theory. They conjecture that it may be driven by intention-based preferences. Players mimicking obstinate players adopt an adversarial bargaining stance at the start of the game which could foster more conflict than predicted by the theory.

Investigating the role of intention-based preferences in bargaining is the motivation of the present paper. Models of bargaining with reputation have shown that initial claims can send signals about bargainers reservation value. And if offers can send a signal about the bargainer's desired outcome, intention-based preference can have a role. Through the sequence of offers and counter-offers in a haggling process, it is not just the beliefs about players' reservation values which are at stake, it is also their mutual perception of kindness or unkindness. Whilst we know little about the mechanisms behind real world negotiation strategies (Goldreich and Pomorski, 2011, for an exception), the art of negotiation is a fully fledged discipline in business degrees. And noticeably, textbooks often give the practical advice not to make an "unreasonable" first offer when initiating a bargaining process (e.g. Raiffa, Richardson and Metcalfe, 2002). 


\section{Experiment}

\subsection{Experimental Design}

We design a two-stage alternating-offer bargaining game with no shrinkage of the pie from the first to the second period (see Figure 1). In a first stage, the Proposer makes an offer on how to divide the money between himself $\left(\mathcal{O}_{P}^{1}\right)$ and the Responder $\left(\mathcal{O}_{R}^{1}=\$ 10-\mathcal{O}_{P}^{1}\right){ }^{4}$ The Responder can then either accept or reject the offer. If the Responder accepts, both players receive the amount corresponding to the Proposer's suggested partition. If he rejects the offer, the Responder makes a counter-offer to the Proposer regarding the split of the money $\left(\mathcal{O}_{P}^{2}, \mathcal{O}_{R}^{2}\right)$. The Responder's counter-offer is then either accepted or rejected by the Proposer. If the Proposer accepts it, the suggested partition is implemented. If the Proposer rejects the counter-offer, both players earn nothing. For simplicity, in the following discussion, we characterise the offers and counter-offers by the amount they ascribe to the Proposer in the suggested split of the pie. We talk of "request" for the Proposer and "offer" for the Responder. ${ }^{5}$

The absence of shrinkage makes the first offer request $\left(\mathcal{O}_{P}^{1}\right)$ costless to reject. Under standard assumptions, in particular for money being the only carrier of utility for the bargainers, all the bargaining power relies in the hand of the Responder who can make the final take-it or leave-it proposition. In the subgame perfect Nash equilibrium of the game, the Responder refuses any initial offer which gives a positive amount to the Proposer and proposes zero in his counter-offer which is accepted by the Proposer. In that sense, the Responder is in a position very similar to a proposer in the ultimatum game. ${ }^{6}$

As discussed in Section 2, research in behavioural game theory has shown that

\footnotetext{
${ }^{4}$ In the remaining, all monetary amounts are in Australian dollars.

${ }^{5}$ In the experiment, the wording was neutral for both players to characterise a proposed split between them and the other player.

${ }^{6}$ Note that while the first offer is costless to reject, it can also be accepted. For that reason, it is not a cheap-talk message but bears a cost for the Proposer: for any offer assigning him less than the full amount, he accepts the possibility to forego higher amounts. An ultimatum game with a pure cheap talk request in a pre-play cheap-talk communication phase was investigated by Rankin (2003). The study unexpectedly found a negative effect of the option to make a request. In light of our results, this finding can be the consequence of the high level of the requests observed in the study (and possibly from the emotional effect of the words "I request" used by the receiver).
} 
bargainers do not care only for money. They also care about the fairness of the split and their reservation value is typically higher than zero. As a consequence, Responders' best strategy is to offer a positive amount to avoid a rejection. Responders do not know the Proposer's reservation value. Our haggling game is therefore characterised by an imperfect information about the players preferences (e.g. minimum acceptable offers). Proposers can use the initial offer to try to influence the Responder's beliefs about their preferences.

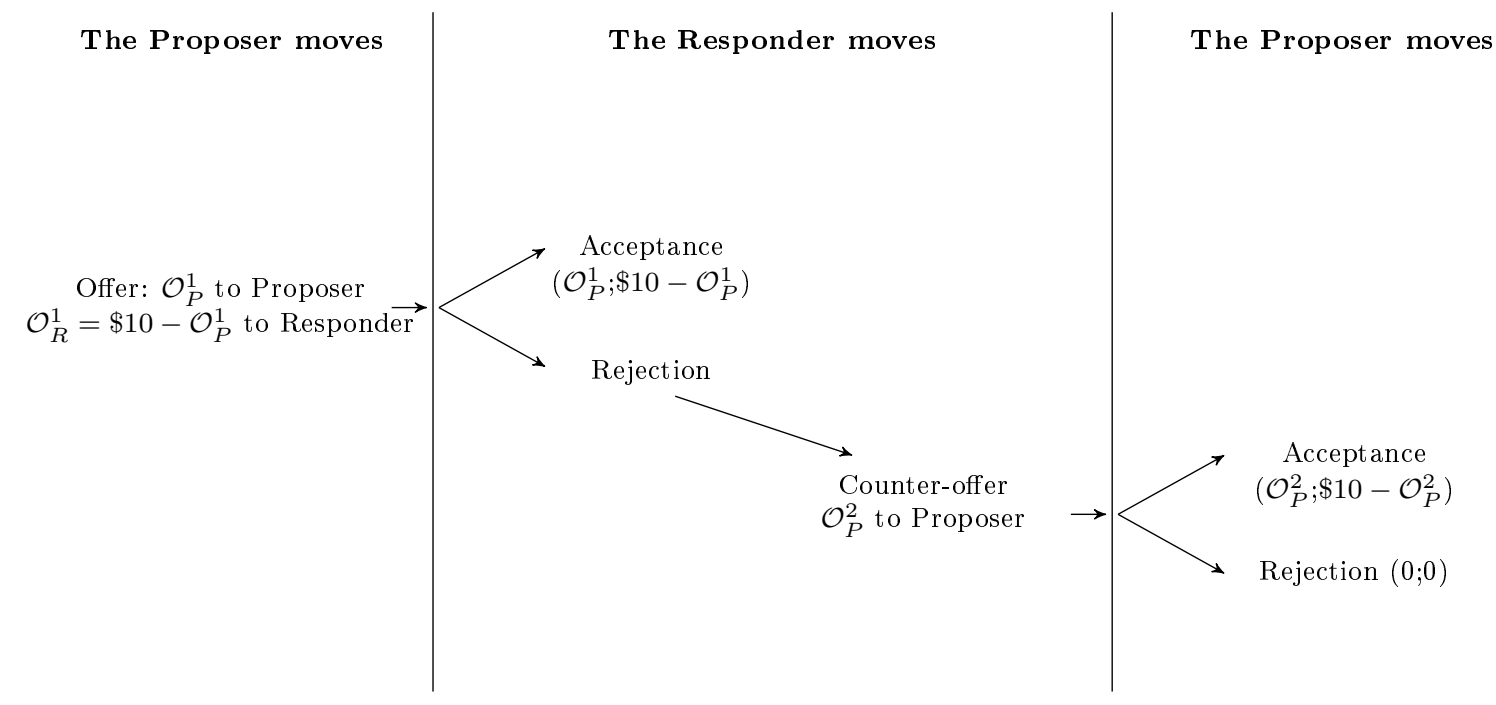

Figure 1: Game tree of our two-stage alternating bargaining game without shrinkage of the pie.

The experiment took place between March and September 2014. We collected data on choices of 158 subjects in total in the bargaining experiment. Each participant played either the Proposer or the Responder (79 participants in each each role). There were ten experimental sessions with 10 to 20 subjects. It was conducted using the experimental software CORAL (Schaffner, 2013) with students from a large university in Australia, recruited via the ORSEE software (Greiner, 2015). After reading the instructions, subjects had to answer a couple of control questions to ensure their understanding of the game and the payoff structure. ${ }^{7}$ Participants were then randomly assigned to the role of Proposer or Responder

\footnotetext{
${ }^{7}$ Participants who answered wrongly to some of these questions received additional explanation until the experimenter was satisfied that they understood the game.
} 
and kept their role during the entire experiment. At the end of the bargaining session, we also elicited participants' beliefs on the intended actions and/or beliefs of the other player. ${ }^{8}$ At the end of the experiment, participants were randomly matched into pairs of one Proposer and one Responder, and payoffs were determined according to their choices and stated beliefs. At no time were subjects informed about the identity of their matched partner. Each session lasted approximately 45 minutes. All subjects received a fixed participation fee of $\$ 3$ and earned on average $\$ 14.30$. The full instructions can be found in appendix.

We used the strategy method to elicit the Responders' decisions and beliefs for each possible offer from the Proposer. This allows us to observe how the Proposer's first offer affects the Responder's subsequent counter-offer. ${ }^{9}$ To avoid experimenter demand effects, we randomly shuffled the presented order of first offers.

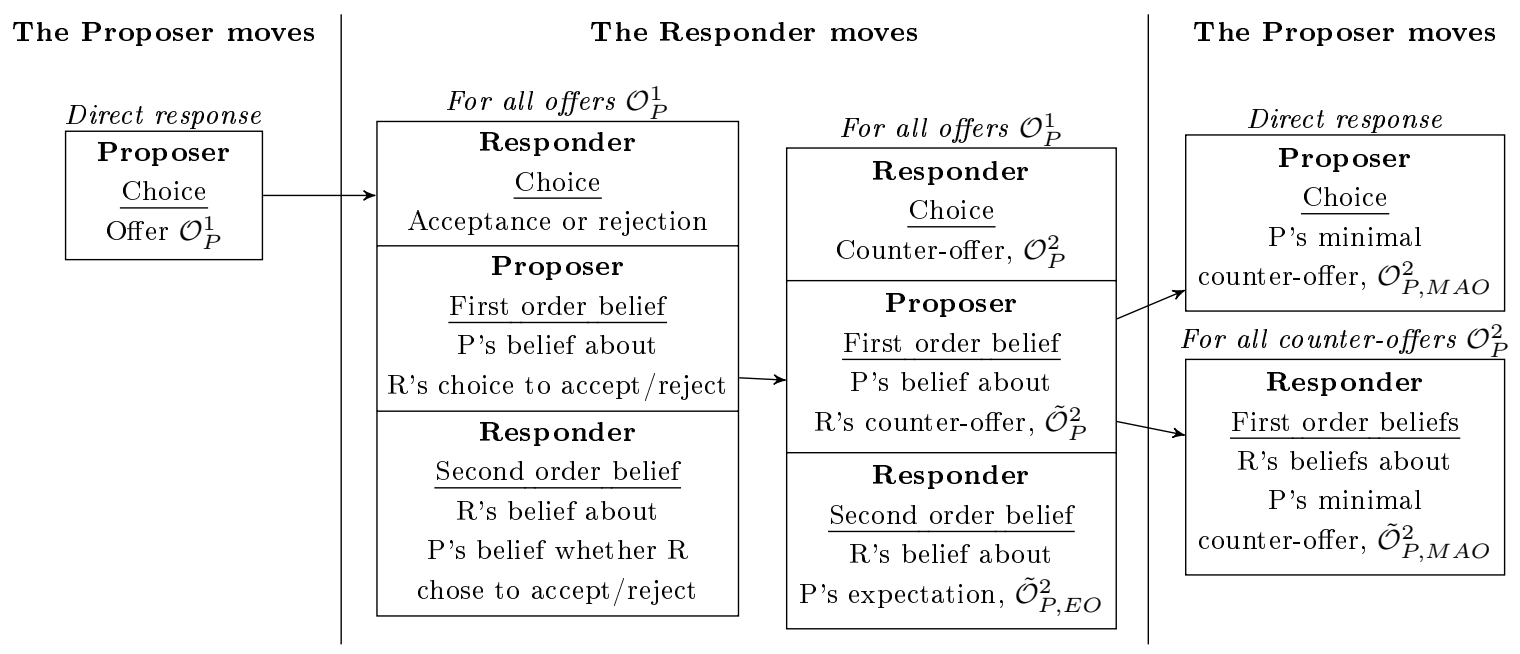

Figure 2: Elicitation of players' strategies and beliefs. Proposer and Responder are designated by the letters $\mathrm{P}$ and $\mathrm{R}$ respectively.

Figure 2 presents all the strategies and beliefs elicited from both players. The

\footnotetext{
${ }^{8}$ When participants made their action decisions, they did not know about the belief-estimation task yet. Following Dufwenberg, Gächter and Hennig-Schmidt (2011), we decided on this timing to avoid any influence on decisions through strategic choice making in order to subjectively simplify subsequent guesswork.

${ }^{9}$ There are potential factors such as a reduction in incentives or a "hot" vs. "cold" effect that might affect the participants' choices by using the strategy method (Zizzo, 2010). However, the experimental evidence does not report any case in which a treatment effect is observed with the strategy method and not with the direct-response method (Brandts and Charness, 2011).
} 
Proposer makes the decision about his initial proposition on how to split the $\$ 10$. In addition, he is asked about his minimum acceptable counter-offer $\left(\mathcal{O}_{P, M A O}^{2}\right)$, i.e. the smallest amount which he would need to receive in order to just accept a Responder's counter-offer. The Responder makes his acceptance/rejection decision for every possible initial offers. If he rejects an offer, he also makes a counter-offer to suggest another split of the $\$ 10$.

In order to understand the potential dynamic initiated by a Proposer's first offer and its effect on a Responder's decision, we elicited participants' first and second order beliefs about their partners' choices and beliefs. It allows us to capture if and how beliefs change as a function of a Proposer's opening offer. Given the abstract nature of first and second order preferences, we designed a novel elicitation procedure representing the question with stylised vignettes of players thinking of other players. Figure 3 represent these pictures. ${ }^{10}$
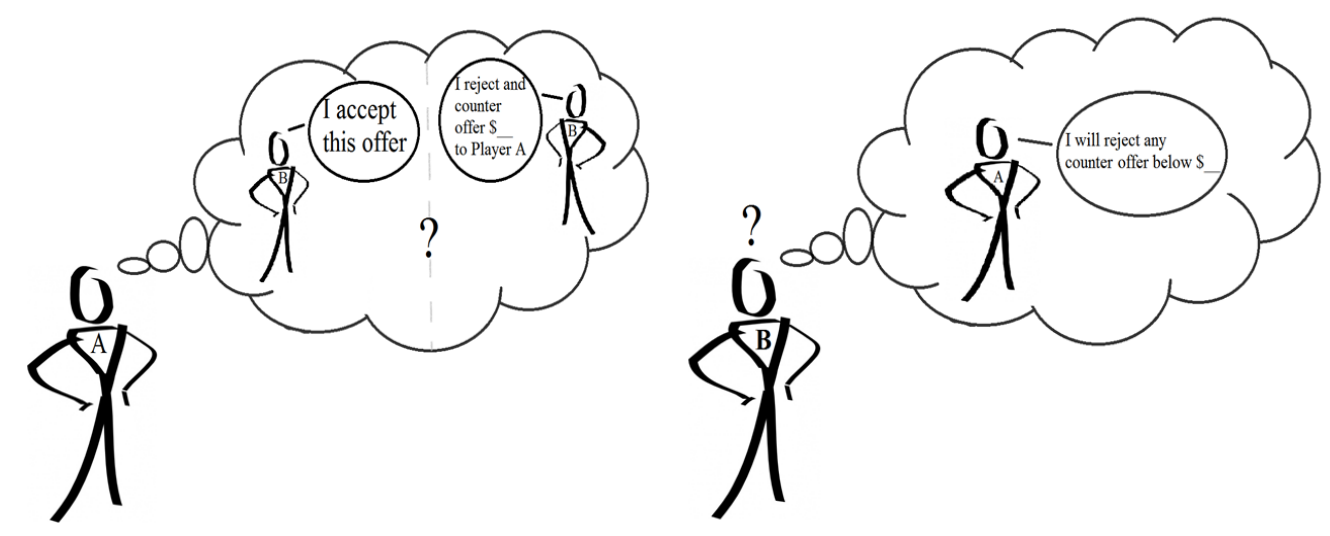

Figure 3: Method to elicit players' beliefs. Right panel: the Proposer (Player A) is asked to consider the Responder minimum acceptable offer. Left panel: the Responder (Player B) is asked to estimate the Proposer propensity to accept an offer and reject a counter-offer.

Using these vignettes, we ask the Proposer to guess whether the Responder will accept or reject his initial offer regarding the split of the $\$ 10$. We do so for all offers that he could have made. In case he expects the Responder to reject the offer, we furthermore elicit the Proposer's guess on how much money the

\footnotetext{
${ }^{10}$ First order beliefs were elicited showing pictures of the player thinking about the action of the other player. Second order beliefs were elicited using the same picture but now representing the other player thinking about the player's thoughts. See experimental material in appendix.
} 
Responder will assign him in the counter-offer. We ask the Responder to guess how the Proposer expects him to react to each of his potential split propositions, i.e. whether the Proposer expects him to accept or reject that particular split. If the Responder thinks that the Proposer expects a rejection, we additionally ask the Responder to guess the Proposer's expectation about the counter-offer in case of rejection $\left(\widetilde{\mathcal{O}}_{P, E O}^{2}\right)$. The Responder's belief about the Proposer's reservation value is conveyed by his belief about the Proposer's minimum acceptable offer $\left(\widetilde{\mathcal{O}}_{P, M A O}^{2}\right)$. This belief is elicited for all possible first offers from the Proposer.

Participants were rewarded $\$ 0.50$ for correct guesses (and only for those) for each belief elicitation question. Given the relative complexity and large number of elicited beliefs, this procedure was chosen to be easy to understand. ${ }^{11}$

\subsection{Third party observers}

In order to gain richer insights in the likely beliefs and feelings of players, we elicited the views from third party observers. We recruited 59 participants to indicate their beliefs about their perception of the Proposers' intention for each of the possible offers presented as hypothetical scenarios. By using third party observers, we avoid making these questions about beliefs and perceptions too salient to the players during the actual experiment. It limits the risk of an experimenter demand effect. It also limits the risk of a false consensus effect whereby a player's beliefs can be influenced by his choices (Bellemare, Sebald and Strobel, 2011). Subjects received a flat payment of $\$ 10$ for a session of roughly 30 minutes.

The survey presented all situations a Responder could have been confronted with (i.e. one scenario for each possible offer made by the Proposer) to the observers. They were asked to consider these hypothetical situations and indicate their beliefs about the motive of the Proposer as well as imagine how they would react if they were to receive these offers as a Responder. The full questionnaire can be found in appendix.

\footnotetext{
${ }^{11}$ This incentive method suffices to elicit the mode of a discrete distribution (Wilcox and Feltovich, 2000; Hurley and Shogren, 2005). Hurley and Shogren (2005) further show that this method is robust to deviations from expected utility maximization and risk neutrality.
} 


\subsection{Definitions and Hypotheses}

We define the Responder's final offer to the Proposer as:

$$
\mathcal{O}_{P}^{R}= \begin{cases}\mathcal{O}_{P}^{1} & \text { if the Responder accepted the first offer } \\ \mathcal{O}_{P}^{2} & \text { if the Responder rejected }\end{cases}
$$

The Responder's belief about the Proposer's minimum acceptable counter offer is $\widetilde{\mathcal{O}}_{P, M A O}^{2}$. Unexpectedly, we observed that, in several cases, Responders expect Proposers to have a minimum acceptable counter offer larger than the initial request $\left(\widetilde{\mathcal{O}}_{P, M A O}^{R, 2}>\mathcal{O}_{P}^{1}\right)$ if it is rejected. We show below that that this pattern does not seem to stem from a misunderstanding but from social preferences triggered by the rejection of the first offer. We therefore also define $\widetilde{\mathcal{O}}_{P, M A O}$ as the minimum acceptable offer the Responder can expect the Proposer to have been willing to accept when starting the game: $\widetilde{\mathcal{O}}_{P, M A O}=\min \left(\mathcal{O}_{P}^{1}, \widetilde{\mathcal{O}}_{P, M A O}^{2}\right)$.

And the Responder's belief about the Proposer's expected final offer is defined as:

$\widetilde{\mathcal{O}}_{P, E O}= \begin{cases}\mathcal{O}_{P}^{1} & \text { if the Responder believes the Proposer expects him to accept } \\ \widetilde{\mathcal{O}}_{P, E O}^{2} & \text { if the Responder believes the Proposer expects him to reject, }\end{cases}$

where $\widetilde{\mathcal{O}}_{P, E O}^{2}$ is the Responder's belief about what the Proposer expects to get in a counter-offer $\left(\mathcal{O}_{P, E O}^{2}\right)$.

Non-cooperative game theory with own-payoff maximising agents would predict that the first stage of the game does not give any bargaining power to the Proposer. The Responder expects the Proposer's minimum acceptable amount to be zero and he therefore ignores any positive amount requested by the Proposer in the first offer.

However, we expect first offers to matter for two reasons. First, experimental evidence suggests that cheap talk can influence players' beliefs prior to a bargaining game (Croson, Boles and Murnighan, 2003; Rankin, 2003; Tingley and Walter, 2011; Kriss, Nagel and Weber, 2013; Anbarci, Feltovich and Gürdal, 2015). Second, we also know from the experimental literature that players have positive minimum acceptable amounts in bargaining games due to social preferences. When bargaining occurs in a situation where players are aware that the population of players 
contains some who will stubbornly refuse low amounts the possibility for a player to signal a desired outcome may play a role in the bargaining process (Abreu and Gul, 2000; Wolitzky, 2012; Embrey, Fréchette and Lehrer, 2014).

First offers may give two types of information about the Proposer's minimal acceptable offer $\left(\mathcal{O}_{P, M A O}^{R}\right)$. First, they reveal that it is not higher than the request since they can be accepted by the Responder. Second, they may give an informative signal about the likely minimal acceptable amount the Proposer would accept in a counter-offer lower than the initial request. A first offer may in particular be perceived as a credible signal that a lower counter-offer would be rejected. We make the following hypothesis:

Hypothesis 1a (Signal of stubborness) A Proposer's first offer can be an informative signal of stubborness and be perceived by the Responder as suggesting that the Proposer would refuse a lower counter-offer.

In bargaining games, players' reservation values are typically thought as arising from their social preferences which lead them to refuse unequal splits. To be credible, a signal of stubborness needs therefore to be associated with reservation values compatible with social preferences. We therefore make the following hypothesis:

Hypothesis 1b (Credibility) A Proposer's first offer will be credible if it request half (or possibly less) of the pie. It will not be credible if it requests more than half.

Models of social preferences would typically predict a preference for an equal split in a pie-splitting game. So Hypothesis $1 \mathrm{~b}$ reflects the idea that credible reservation values can be positive but bounded by the equal split.

When introducing intention-based preferences, first offers can play another role by influencing the belief of the Responder about the Proposers' intentions. The Responder may not only care about the amount the Proposer wants to secure but also the amount he is willing to grant to the Responder. We therefore make the two following hypotheses:

Hypothesis 2a (Signal of kindness) An offer below the equal split can be perceived as kind by the Responder as it signals that the Proposer is willing to grant a larger share to the Responder. 
Hypothesis 2b (Signal of unkindness) An offer above the equal split can be perceived as unkind by the Responder as it signals that the Proposer is willing to grant a smaller share to the Responder.

We conjecture that these two types of signal, stubborness and kindness, will both play a role determining how a first offer influences the final bargaining outcome. From our hypotheses we expect a pattern to emerge:

Hypothesis 3 (Balance of stubborness and kindness) A Proposer's final payoff vary in an inverted U-shape fashion as a function of the level of his first offer. An intermediary first offer, balancing a credible signal of stubborness without signalling unkindness, delivers the highest payoff.

Hypothesis 3 reflects our expectation that small first offer requests may be perceived as kind but signal a low reservation value and large requests may be perceived as unkind and do not signal a credible stubborness. ${ }^{12}$ The joint elicitation of strategies and beliefs in our bargaining game allows us to investigate whether this pattern appears and whether it is driven by perception of stubborness and kindness.

\section{Data and Results}

\subsection{Bargaining outcomes}

The outcomes of the bargaining interactions are summarized in Table 1. In the first offer, the Proposers request on average $\$ 5.5$ or 55 percent of the pie. In contradiction with standard predictions if players are self-centred, the final offer from the Responder $\left(\mathcal{O}_{P}^{R}\right)$ is substantial, on average $\$ 4.7$. Final payoffs are on average balanced between the Proposers and the Responders with $\$ 4.23$ and $\$ 4.25$,

\footnotetext{
${ }^{12}$ It is not simply explained by the effect of first offer on the perceived minimum acceptable offer from the Proposer. Suppose we observe that high requests are associated with low counter-offers. An alternative explanation to Hypothesis 3 would be that high offers signal a low credibility of the bargainer and possibly a lower MAO than a smaller request. Our elicitation of players' beliefs allows us to disentangle these two possible reasons which would lead higher initial requests to be associated with lower counter-offers.
} 


\begin{tabular}{lcccccccc}
\hline $\begin{array}{c}\text { Proposer } \\
\text { offer } \\
\mathcal{O}_{P}^{1}\end{array}$ & $\begin{array}{c}\text { Responder } \\
\text { rejection } \\
\text { Rate }\end{array}$ & $\begin{array}{c}\text { Responder } \\
\text { counter-offer } \\
\mathcal{O}_{P}^{2}\end{array}$ & $\begin{array}{c}\text { Responder } \\
\text { final offer } \\
\mathcal{O}_{P}^{R}\end{array}$ & $\begin{array}{c}\text { Proposer } \\
\text { rejection }\end{array}$ & $\begin{array}{c}\text { Proposer } \\
\text { MAO } \\
\mathcal{O}_{P, M A O}^{2}\end{array}$ & $\begin{array}{c}\text { Proposer } \\
\text { payoffs }\end{array}$ & $\begin{array}{c}\text { Responder } \\
\text { payoffs }\end{array}$ \\
\hline $\begin{array}{l}\text { For offers chosen by the Proposers } \\
\text { Mean }\end{array} 5.53$ & $32 \%$ & 4.12 & 4.73 & $48 \%$ & 4.68 & 4.23 & 4.25 \\
SD & $(1.24)$ & & $(1.11)$ & $(.79)$ & & $(1.59)$ & $(1.83)$ & $(1.84)$ \\
\hline $\begin{array}{l}\text { For all possible offers } \\
\text { Mean } 5.00\end{array}$ & $48 \%$ & 4.22 & 3.49 &. & &. &. & \\
SD & $(3.16)$ & & $(1.40)$ & $(1.88)$ & & & & \\
\hline
\end{tabular}

Table 1: Summary statistics.

respectively. It is a striking result given that the first offer should not give bargaining power to the Proposer under standard assumptions. As a matter of fact, the Proposer should have the same bargaining power as the receiver in ultimatum games. And receivers in ultimatum games typically get much less than half the pie (Camerer, 2003, ultimatum offers are on average around of 30-40 percent). We therefore observe that being able to make a first offer allows the Proposer to get a share of the pie almost equal to the one of the Responder.

Proposers' relatively high average earnings are driven by two mechanisms: First, even though first offers are costless to reject, they are accepted most of the time (68 percent of the bargaining situations). Second, even when first offers' requests are rejected, the counter-offer still tends to be substantial. Rejected first offers' requests $\left(\mathcal{O}_{P}^{1}\right)$ are on average $\$ 6.64$ and the subsequent counter-offers $\left(\mathcal{O}_{P}^{2}\right)$ are on average $\$ 4.1$.

\subsection{Proposers' choices}

The large majority of Proposers make a 50:50 split-offer (Figure 4). Only two Proposers request less than $\$ 5$ by asking $\$ 4$ and nobody asked less than this amount. A few Proposers asked for more than $\$ 5$. Most of these requests are concentrated at $\$ 6$ with only few Proposers asking for more than this amount.

Although the final level of counter-offers is on average above $\$ 4$, counter-offers are rejected by the Proposer 52 percent of the time. When the counter-offer is below $\$ 5$, it is rejected over 80 percent of times. These rejection rates are high compared to ultimatum games (Camerer, 2003, lists 16 studies with typical average rejection in the range of 10-30 percent). Rejections are driven by the Proposers' 

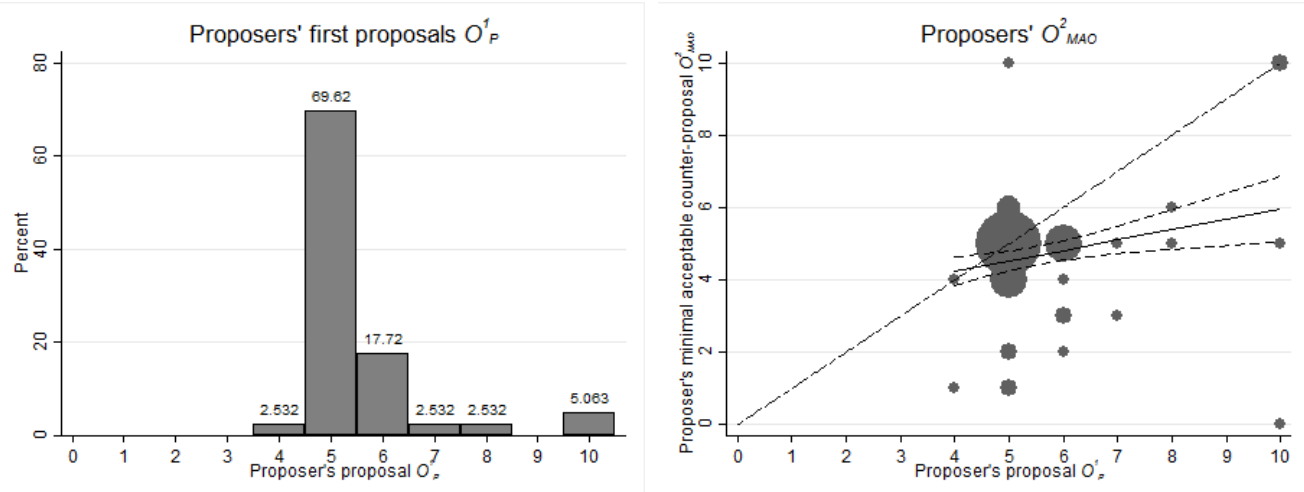

Figure 4: The Proposer's decisions. The left panel shows the distribution of the first offers. The left panel shows their minimum acceptable counter-offers $\left(\mathcal{O}_{P, M A O}^{2}\right)$ and the right panel their final payoffs with a superimposed regression line and its confidence interval.

average level of minimum acceptable counter-offer $\left(\mathcal{O}_{P, M A O}^{2}\right)$ of $\$ 4.7$. It is rather high compared to what is observed in typical ultimatum studies, which is around 20-30 percent of the pie size (e.g. Blount, 1995; Straub and Murnighan, 1995).

For most Proposers who make an equal split offer $\left(\mathcal{O}_{P}^{1}=5\right)$, their minimum acceptable offer is also the equal split $\left(\mathcal{O}_{P, M A O}^{2}=5\right)$. A request of a fair split is therefore a rather informative signal that the Proposer is likely to reject an unequal split. Furthermore, as can be seen on the right panel of Figure 4, there is a positive relationship between the Proposers' first offer requests $\left(\mathcal{O}_{P}^{1}\right)$ and their minimum acceptable offers $\left(\mathcal{O}_{P, M A O}^{2}\right)$. Overall, these patterns indicate that the level of the first offer contains some information about the likelihood that the Proposer rejects low counter-offers, even though demanding offers $\left(\mathcal{O}_{P}^{1}>5\right)$ are not a true indication of the Proposer's reservation value.

These results support Hypothesis 1a. Through their first offers, Proposers send an informative signal about their stubborness. In our sample a substantial proportion of proposers adopt an "obstinate" strategy where they commit to refuse counter-offers below $\$ 5$ while making an offer of $\$ 5$. The literature on bargaining with reputation has shown that the existence of obstinate players gives weight to initial signals of stubborness and allows players sending the signal to claim a substantial part of the pie Abreu and Gul (2000); Wolitzky (2012). We observe indeed that the final payoffs of Proposers and Responders are almost equal in 
our design. The possibility to make a first offer coupled with the existence of a substantial amount of obstinate players seems to give bargaining power to the Proposer even though his initial offer is costless to reject.

\subsection{Responders' reaction to the opening offer}

Responders accept most of the time any offer where the Proposer requests $\$ 5$ or less. For initial requests $\left(\mathcal{O}_{P}^{1}\right)$ above $\$ 5$, the acceptance rate falls sharply and quickly goes near zero. The acceptance rate of Responders (as well as the associated beliefs from the two players) is represented in the left panel of Figure 5 .

\section{Result 1 (Acceptance of initial offers)}

The Responders' accept most requests $\left(\mathcal{O}_{P}^{1}\right)$ which are below or equal to $\$ 5$. The acceptance rate falls quickly for offers requesting more than the equal payoff allocation. For requests of $\$ 7$ and above it is close to zero.

It is worth noting that while players deviate from the predictions of a standard model with money maximising agents, they have correct beliefs about the game. The Proposers' expectations regarding the Responders' acceptance decision as well as the Responders' belief about the Proposers' expectations are on average quite accurate.

The Responders' final offer can be seen in the right panel of Figure 5. The Responders' average final offer $\left(\mathcal{O}_{P}^{R}\right)$ follows closely the 45 degree line up to an offer of approximately $\$ 5$. This pattern reflects the high acceptance rate for low offers. The observed kink around offers of $\$ 5$ reflects the sudden drop in the acceptance rate above this number. Final offers stop increasing above $\$ 5$, they actually start declining for first offers requesting more than $\$ 6$. This downward slope is significant using an OLS regression for offers above $\$ 5(p<0.001)$.

\section{Result 2 (Counter-offers' as a function of first offers)}

The Responders' average final offer increases with the opening offer requests if it is below 50 percent of the pie. It decreases with for higher requests of the pie.

Such a decrease of counter-offers suggests that a high first offer carries information for the Responder. One possibility is that this information is about the 

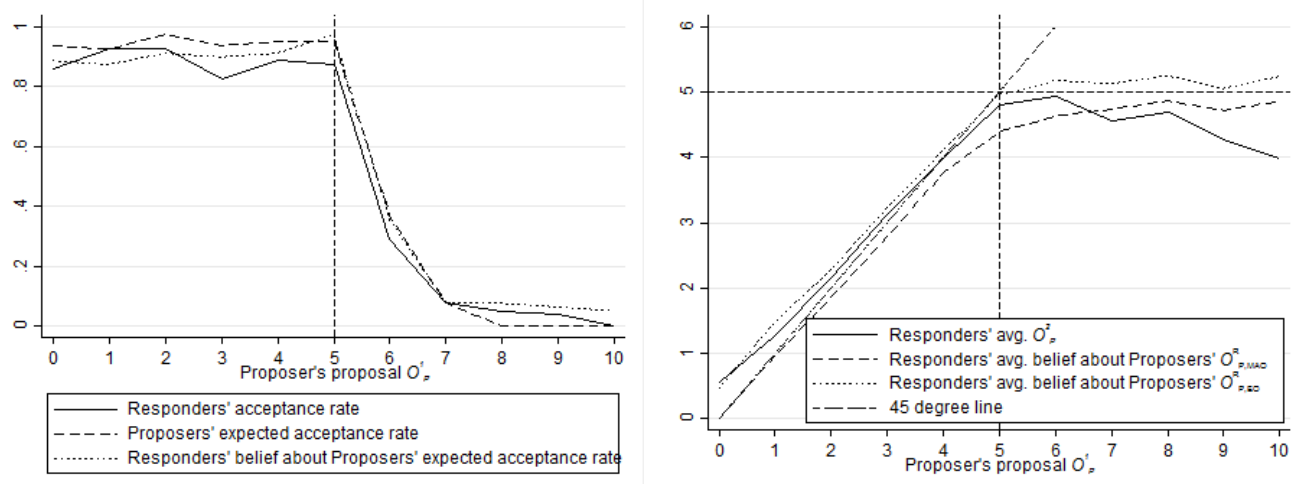

Figure 5: Responder's reaction to the first offer. The left panel shows a) The Responders' average acceptance rate; b) The Proposers' average expected acceptance rate; c) The Responders' average belief about the Proposers' expected acceptance rate. The right panel shows the Responders' a) average final offer (average of $\mathcal{O}_{P}^{R}$ ), alongside his beliefs about b) the expectation of the Proposer $\left(\widetilde{\mathcal{O}}_{P, E O}^{R}\right)$ and c) the Proposer minimum acceptable offer $\left(\widetilde{\mathcal{O}}_{P, M A O}^{R}\right)$.

Proposer's minimal acceptable offer. High initial requests could be interpreted as a bluff hiding a low reservation value. Elicited beliefs do not point to such an explanation. In line with Hypothesis $1 \mathrm{~b}$, offers requesting more than $\$ 5$ do not seem to be seen as credible signals of stubborness. They do not impact the Responders' beliefs on the Proposer's minimal acceptable offer and his expected offer. High initial requests seem to have the same effect as cheap talk.

\section{Result 3 (Demanding offers and Responders' average beliefs)}

Offers requesting more than the equal payoff split are generally not interpreted as:

(i) Signalling a credible indication of a stubborn bargaining stance (high $\widetilde{\mathcal{O}}_{P, M A O}^{R}$ ).

(ii) Signalling a higher payoff expectation from the Proposer (high $\widetilde{\mathcal{O}}_{P, E O}^{R}$ ).

Another possibility is that the Responder draws information from the initial offer about the kindness of the Proposer as suggested by hypotheses $2 \mathrm{a}$ and $2 \mathrm{~b}$. Indeed, the pattern of Responders' final offers is in line with the conjecture from Hypothesis 3 whereby final offers are jointly influenced by perceived stubborness and kindness from the first offer. Final offers exceed the Responder's belief about the Proposer's minimum acceptable offer $\left(\mathcal{O}_{P, M A O}\right)$ up to a level of approximately 
$\$ 7$ (Figure 5). In several cases, the Responder accepts a small request by the Proposer even though he believes he could try to claim more for himself. Very modest requests from the Proposer first offer (up to approximately $\$ 4$ ) are sometimes even followed by a counter-offer offering the Proposer more than what he had asked for $\left(\mathcal{O}_{P}^{R}\right.$ above the 45 degree line).

Once first offer requests go beyond $\$ 7$, though, the Responders' final offer $\left(\mathcal{O}_{P}^{R}\right)$ falls on average short of his belief of the Proposer's minimum acceptable offer $\left(\widetilde{\mathcal{O}}_{P, M A O}^{R}\right)$. The Responders react to demanding offers by making counteroffers which are on average lower than what they believe the Proposer's minimum acceptable offer is. This behaviour can be interpreted as indicating a desire to punish the Proposer. It is costly as it is likely to lead to a rejection from the Proposer and therefore to a null payoff for both players. The level of counteroffers drops as initial requests tend towards the full amount of the pie.

The pattern of such punishing behaviour is displayed in Figure 6. The left panel shows the difference between the Responder's counter-offer $\left(\mathcal{O}_{P}^{2}\right)$ and his belief about the Proposer's minimum acceptable offer $\left(\widetilde{\mathcal{O}}_{P, M A O}^{R}\right)$ for each initial offer. The right panel shows the proportion of punishing counter-offers $\left(\mathcal{O}_{P}^{2}<\widetilde{\mathcal{O}}_{P, \text { MAO }}^{R}\right)$ for each initial offer. For a very high initial request, more than 40 percent of the counter-offers can be considered as punishing.

\section{Result 4 (Reciprocal answers to first offers)}

- When the Proposer requests less than the equal split in the first offer $\left(\mathcal{O}_{P}^{1}<\right.$ $5)$, the Responders' average final offer $\left(\mathcal{O}_{P}^{R}\right)$ exceeds the Proposer's initial request $\left(\mathcal{O}_{P}^{2}>\mathcal{O}_{P}^{1}\right)$.

- When the Proposer requests more than the equal split in the first offer $\left(\mathcal{O}_{P}^{1}>\right.$ 5), the Responders' average final offer decreases and drops below their average belief about the Proposer's minimum acceptable offer. Responders seem willing to terminate the bargaining without an agreement as a consequence of the Proposer's first offer. 

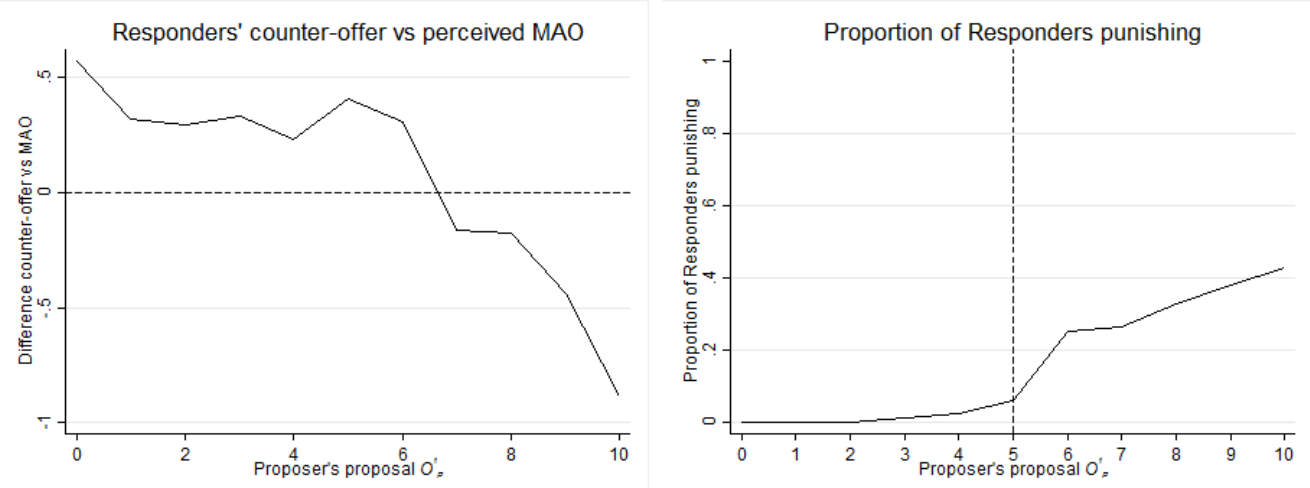

Figure 6: Responders' punishing behaviour. The left panel shows the average difference between the Responders' final offer and their belief about the Proposer's minimum acceptable offer $\left(\widetilde{\mathcal{O}}_{P, M A O}^{R}\right)$. The right panel shows the proportion of Responders making a punishing counter-offer for each offer. The Responder is said to punish the Proposer if the counter-offer is below what he believes is the Proposer's minimum acceptable offer $\left(\mathcal{O}_{P}^{2}<\mathcal{O}_{P, M A O}\right)$.

\subsection{External observers' perceptions}

To get further insights into how Proposers' offers may be interpreted we collected the views of external observers. The observers were asked emotionally weighted questions about their perception of the game. In particular, they were asked about the kindness of the Proposer and his actions. They were also asked how they would feel if they were the Responder. Two additional questions were aimed at giving further insights into the mechanisms driving punishing counter-offers. They were asked whether they would consider making a counter-offer so low that it would likely be rejected. They were also asked whether they would choose to end the game without an agreement if they had this possibility (leading to a payoff of zero for both players).

To ascertain whether observers' perception of the interaction is relevant, we first check whether their beliefs about the players' choices match the players' behaviour. Noticeably, the observers' expectations about players' choices and beliefs in the game closely resemble the actual pattern of answers observed in the experiment (see Figure 7). This result suggests that they have a good understanding of the game and the likely state of mind of the Proposers and Responders in each situation.

We asked the observers about their perceived intentions and perceptions of 

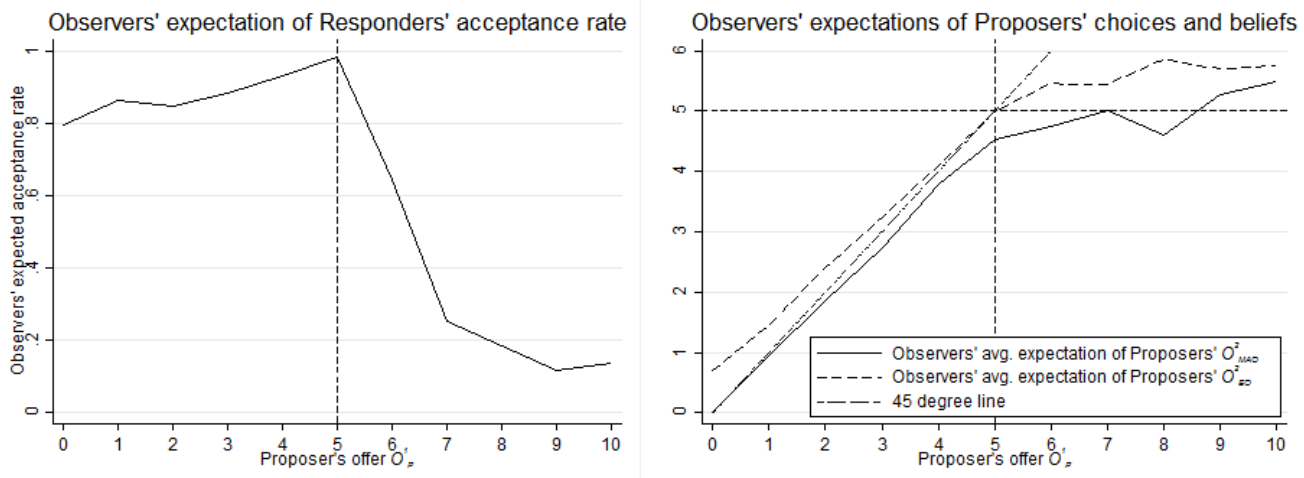

Figure 7: Observers' expectations about the Responders' acceptance rate (left panel) and about Proposers' expected final offer $\left(\mathcal{O}_{P, E O_{P}^{R}}\right)$ and their minimum acceptable offer $\left(\mathcal{O}_{P, M A O}\right)$ (right panel).

the different bargaining situations. Figure 8 displays the answers about their perception of the Proposer's motive. Unsurprisingly, most observers regard the Proposer as "fair" when making an equal split offer $\left(\mathcal{O}_{P}^{1}=5\right)$. Offers requesting more than $6\left(\mathcal{O}_{P}^{1} \geq 6\right)$ are perceived as indicating "selfishness". Similarly, half of the observers interpret such offers as indicating a desire to secure more than half of the $\$ 10$. Proposers making offers requesting almost all the pie $\left(\mathcal{O}_{P}^{1} \geq 9\right)$ are classified as "nasty" by a third of the observers. Observers generally do not tend to interpret first offers as being used strategically by the Proposer to suggest to the Responder a minimum acceptable offer $\left(\mathcal{O}_{P, M A O}\right)$ higher than it is.

Additionally, we asked the observers about their feelings if they were to be faced with each possible opening offer as a Responder. Figure 9 represents the fraction of observers experiencing a particular feeling. Observers tend to feel "good" and "happy" for offers requesting less than half the pie $\left(\mathcal{O}_{P}^{1} \leq 5\right)$ and "angry" and "insulted" for offers requesting substantially more than half $\left(\mathcal{O}_{P}^{1} \geq 7\right)$.

The answers from the external observers confirm that the level of first offers may be interpreted by the Responder as signalling the Proposer's intentions. In particular, first offers with a large request are likely to be associated with unkind intentions and to trigger negative emotions. Using these answers and the actual behaviour observed in the experiment we can investigate what drives the intentionbased preferences. 

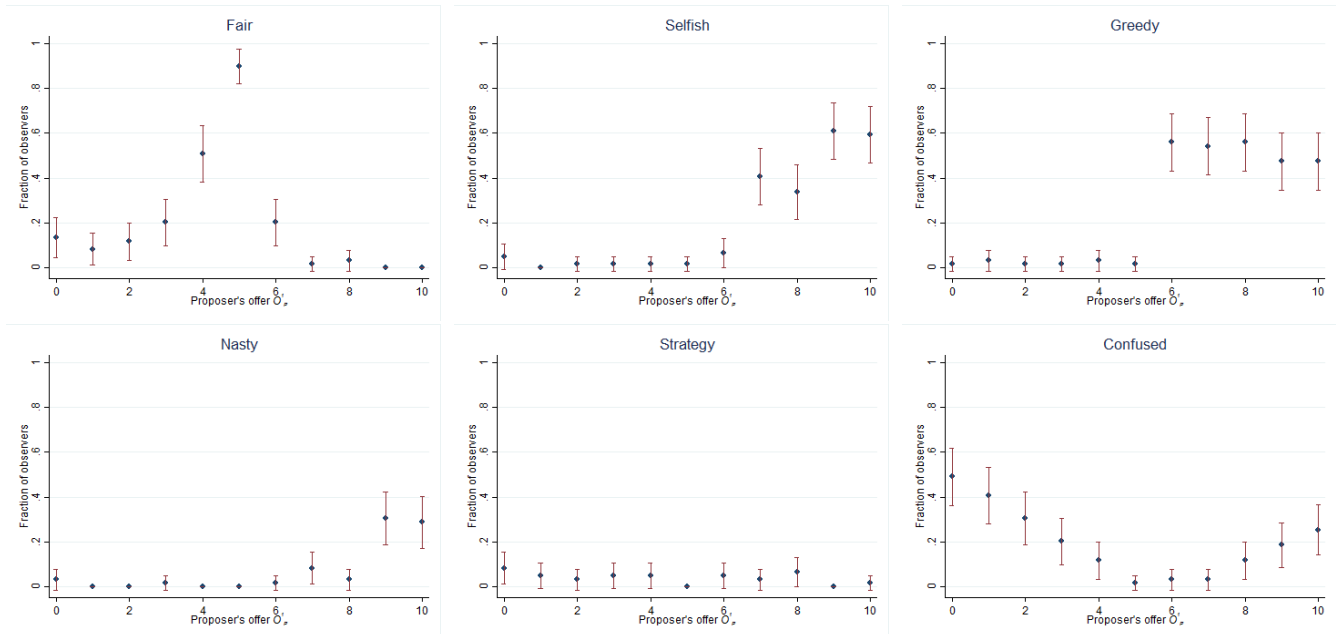

Figure 8: Observers' views on the motives behind the Proposer's different opening offers.
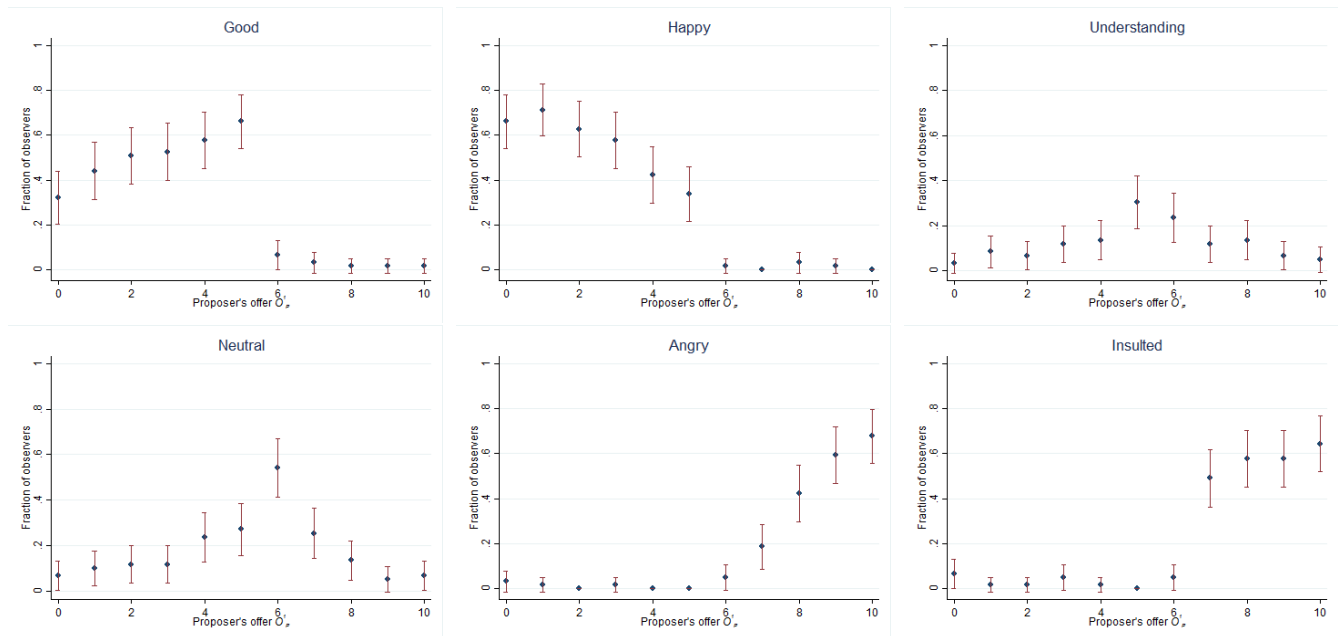

Figure 9: Observers' feelings when faced with the Proposer's different opening offers. 


\subsection{What drives these intention-based preferences?}

Our experimental design allows us to investigate the mechanisms behind the Responder's reaction to the Proposer's offer.

\subsubsection{Psychological game theory models of reciprocity}

According to the reciprocity approaches by Rabin (1993) as well as Dufwenberg and Kirchsteiger (2004) and Falk and Fischbacher (2006), perceived kindness depends crucially on players' second-order beliefs. In our bargaining game, the more the Responder believes the Proposer expects to accrue for himself from the final payoff allocation, the less kind the Proposer's choice is perceived. Hence, the higher the Responder's belief about the Proposer's payoff expectations $\left(\widetilde{\mathcal{O}}_{P, E O}^{R}\right)$, the less kind the Proposer's choice is interpreted and in turn the less kind the Responder's response should be. Our elicitation of first and second order beliefs in this experiment allows us to investigate the empirical predictions of psychological game theory in this bargaining situation.

We find that first offers have an effect on the Responders' beliefs about the Proposers' expectations. First offers requesting less than $\$ 5$ lead Responders to believe that Proposers expect less than half the pie $\left(\widetilde{\mathcal{O}}_{P, E O}^{R}<5\right)$. In the perspective of psychological game theory, this belief about a low payoff expectation from the Proposer can explain the existence of kind final offers from Respondents $\left(\mathcal{O}_{P}^{R}>\right.$ $\left.\widetilde{\mathcal{O}}_{P, M A O}^{R}\right)$ as positive reciprocity.

For first offers requesting more than $\$ 5$, Respondents' beliefs about the Proposer's expectation stop rising and stay close to $\$ 5$. This pattern in Figure 5 suggests that the punishing counter-offers observed for demanding first offers are unlikely to be driven by the Responder's perception of the Proposer's expectations. We however observe some heterogeneity in Responders' beliefs. In order to test whether punishing counter-offers may be driven by those Responders who interpret large requests in first offers as signalling higher expectations by the Proposer, we regress Responders' final offers on their second order beliefs for first offers requesting more than half the pie $\left(\mathcal{O}_{P}^{1}>5\right)$. The first column of Table 2 presents the result of this regression. The final offer is slightly affected by the level of expectations, but the sign is positive, in contradiction with the prediction from 
psychological game theory models of reciprocity. We also observe that the level of the first offer request is a significant predictor of the level of the final offer, even after controlling for the Responder's beliefs about the Proposer's expectations and reservation value. In that sense, these specific beliefs do not seem to capture all the effect induced by the first offer.

To investigate the role of second order beliefs further, we use the external observers' beliefs to predict their answers about how they would hypothetically react in this bargaining situation. First, we look at the effect of the belief about the Proposer's expectations $\widetilde{\mathcal{O}}_{P, E O}^{R}{ }^{13}$ on the propensity of observers to want to end the negotiation or to make a punishing counter-offer. Columns 2 and 3 of Table 2 present the results of these regressions. The perception of Proposers' expectations seems to have no effect on the observers' decision to react unkindly. Second, we use another question eliciting the observer's belief in a simpler way. We asked observers whether they believe that an offer reflected a desire by the Proposer to secure the larger share of the pie. We use this variable as a dummy regressor in Column 4 and 5 of Table 2. Here again, we find no evidence that this belief has an effect on the propensity of the observer to opt for an unkind behaviour. Noticeably, the level of the first offer is a clear predictor of the punishing behaviour even after controlling for these beliefs. The effect of the first offer on the level of the counter-offer seems not to be driven by these beliefs.

\section{Result 5 (Final offers not driven by beliefs on Proposer's expectation)} Above a first offer request of $\$ 5$ :

(i) The level of the final offer is not negatively correlated with the Responder's perception of the Proposer's expectations $\left(\widetilde{\mathcal{O}}_{P, E O}^{R}\right)$.

(ii) The probability to make a punishing counter-offer $\left(\mathcal{O}_{P}^{2}<\widetilde{\mathcal{O}}_{P, M A O}^{R}\right)$ is not correlated with these perceived expectations $\left(\widetilde{\mathcal{O}}_{P, E O}^{R}\right)$.

These results do not sit easily with an explanation relying on psychological game theory models of reciprocity. While the perceived expectations $\left(\widetilde{\mathcal{O}}_{P, E O}^{R}\right)$ may explain the kind answers for offers requesting less than the equal split $\left(\mathcal{O}_{P}^{1}<5\right)$,

\footnotetext{
${ }^{13}$ This is the belief of observers. As observers put themselves in the shoes of the Responder, we keep the same notation as the belief elicited from Responders.
} 
Table 2: Role of first and second order beliefs on the final offer from the Responder and the hypothetical choice of observers to end the negotiation or punish the Proposer.

\begin{tabular}{|c|c|c|c|c|c|}
\hline & \multirow{3}{*}{$\begin{array}{c}(1) \\
\frac{\text { Responders' actions }}{\mathcal{O}_{P}^{R}} \\
\end{array}$} & \multirow{2}{*}{\multicolumn{4}{|c|}{$\begin{array}{l}(3) \\
\text { Observers' answers }\end{array}$}} \\
\hline & & & & & \\
\hline & & End neg. & Punishing $\mathcal{O}_{P}^{2}$ & End neg. & Punishing $\mathcal{O}_{P}^{2}$ \\
\hline$\widetilde{\mathcal{O}}_{P, E O}^{R}$ & $\begin{array}{l}0.14^{*} \\
(2.24)\end{array}$ & $\begin{array}{c}-0.01 \\
(-0.82)\end{array}$ & $\begin{array}{c}0.00 \\
(0.12)\end{array}$ & & \\
\hline$\widetilde{\mathcal{O}}_{P, M A O}^{R}$ & $\begin{array}{c}0.14 \\
(1.60)\end{array}$ & $\begin{array}{c}0.00 \\
(0.23)\end{array}$ & $\begin{array}{l}0.04^{+} \\
(1.88)\end{array}$ & $\begin{array}{c}0.00 \\
(0.02)\end{array}$ & $\begin{array}{l}0.04^{*} \\
(2.04)\end{array}$ \\
\hline $\mathcal{O}_{P}^{1}$ & $\begin{array}{c}-0.23^{* * *} \\
(-5.38)\end{array}$ & $\begin{array}{c}0.11^{* * *} \\
(5.29)\end{array}$ & $\begin{array}{c}0.10^{* * *} \\
(4.40)\end{array}$ & $\begin{array}{c}0.11^{* * *} \\
(5.29)\end{array}$ & $\begin{array}{c}0.10^{* * *} \\
(4.33)\end{array}$ \\
\hline $\begin{array}{l}\text { Wants larger } \\
\text { share }\end{array}$ & & & & $\begin{array}{c}0.04 \\
(0.74)\end{array}$ & $\begin{array}{l}-0.05 \\
(-0.76)\end{array}$ \\
\hline Constant & $\begin{array}{c}4.93^{* * *} \\
(8.26)\end{array}$ & $\begin{array}{c}-0.53^{* *} \\
(-3.19) \\
\end{array}$ & $\begin{array}{l}-0.44^{*} \\
(-2.41)\end{array}$ & $\begin{array}{c}-0.60 * * * \\
(-3.71)\end{array}$ & $\begin{array}{l}-0.39^{*} \\
(-2.08)\end{array}$ \\
\hline Observations & 395 & 295 & 293 & 295 & 293 \\
\hline
\end{tabular}

For offers $\mathcal{O}_{P}^{1}>5$, Robust standard errors in brackets, clustered by participants.

$+\mathrm{p}<0.10,{ }^{*} \mathrm{p}<0.05,{ }^{* *} \mathrm{p}<0.01,{ }^{* * *} \mathrm{p}<0.001$ 
they don't seem to be able to explain the unkind counter-offers observed for offers requesting more than the equal split $\left(\mathcal{O}_{P}^{2}>5\right)$.

\subsubsection{Spitefulness and wounded pride}

Levine (1998)'s model of spitefulness provides an alternative way to explain an unkind response to an unkind first offer. Spiteful behaviour is here not driven by a belief about the other players's expectation but rather about his type (e.g. selfish, altruist). Levine's model suggests that, if a negative reaction is observed from the external observer, the inference about the Proposer's type should be driving it.

The answers from the observers about their beliefs and emotional state of mind when faced with each first offer can help us investigate this possibility. We asked our observers about their feelings associated with the respective offer (e.g. happiness, anger, insult) and about their perception of the Proposer's type (e.g. fair, selfish, strategical). The Levine model would suggest that unkind answers to demanding first offers would be driven by beliefs about the Proposer's type rather than about his expectations.

Another potential explanation is a concern for pride and self-esteem (Bénabou and Tirole, 2006; Ellingsen and Johannesson, 2008) which can be associated to a demand for respect in social interactions (Eriksson and Villeval, 2012) and preferences for a high status in social interactions (Besley and Ghatak, 2008; Heffetz and Frank, 2008). The observed effect of the feeling to be "insulted" is compatible with a concern for self-esteem triggering negative reactions from the Responders. It is in line with the suggestion by Straub and Murnighan (1995) and Yamagishi et al. (2012) that players react with "wounded pride" to unkind moves from other players. They conjecture that the rejection of low offers in the ultimatum game is a way to re-assert an equality in status which is undermined by a low proposal. The same mechanism could be at play here, with a lower counter-offer from the Responder being a way reverse an asymmetry in status in favour of the Proposer.

We first regress positive and negative emotional reactions of the observer on their beliefs. Table 3 presents the results of these regressions. Overall the belief about the Proposer's expectations only predicts one emotion (happiness) and it does not predict the negative emotion of anger or the feeling of insult, which we 
would have expected if they were driving the Proposers' punishing counter-offers. Conversely, we find that beliefs about the Proposers' types are significantly predicting positive and negative emotions. In particular the belief that the Proposer is "fair" or "kind" decreases "anger" and the feeling of being "insulted", while the belief that the Proposer is "selfish" or "nasty" increases these negative emotions.

To look at how these beliefs predict the observers' hypothetical choices, we regress the choice to end the negotiation or to make a punishing counter-offer on these different beliefs (columns 4-5) and also include emotional reactions in extended specifications (columns 6-7). When doing so, the belief about the Proposer's expectations $\left(\widetilde{\mathcal{O}}_{P, E O}^{R}\right)$ is most often not significant. In comparison, beliefs about the Proposer's type help explain the observer's choice. The belief that the Proposer is "fair" or "kind" significantly decreases the probability to make a punishing counter-offer (column 5). Overall, we observe that the answers to the questions about the type of the Proposer are more predictive than the answers about the Proposer's expectations. And when including the emotions, the feeling of happiness decreases the chance to make a punishing counter-offer while the feeling of being insulted increases the chance of ending the negotiation.

Result 6 Unkind counter-offers for first offer requests above $\$ 5$ :

1. Do not seem to be driven by the Responder's belief about the Proposer's expectations;

2. Are correlated with the Responder's belief about the type of the Proposer;

3. Are correlated with the feeling of being insulted by the first offer. 


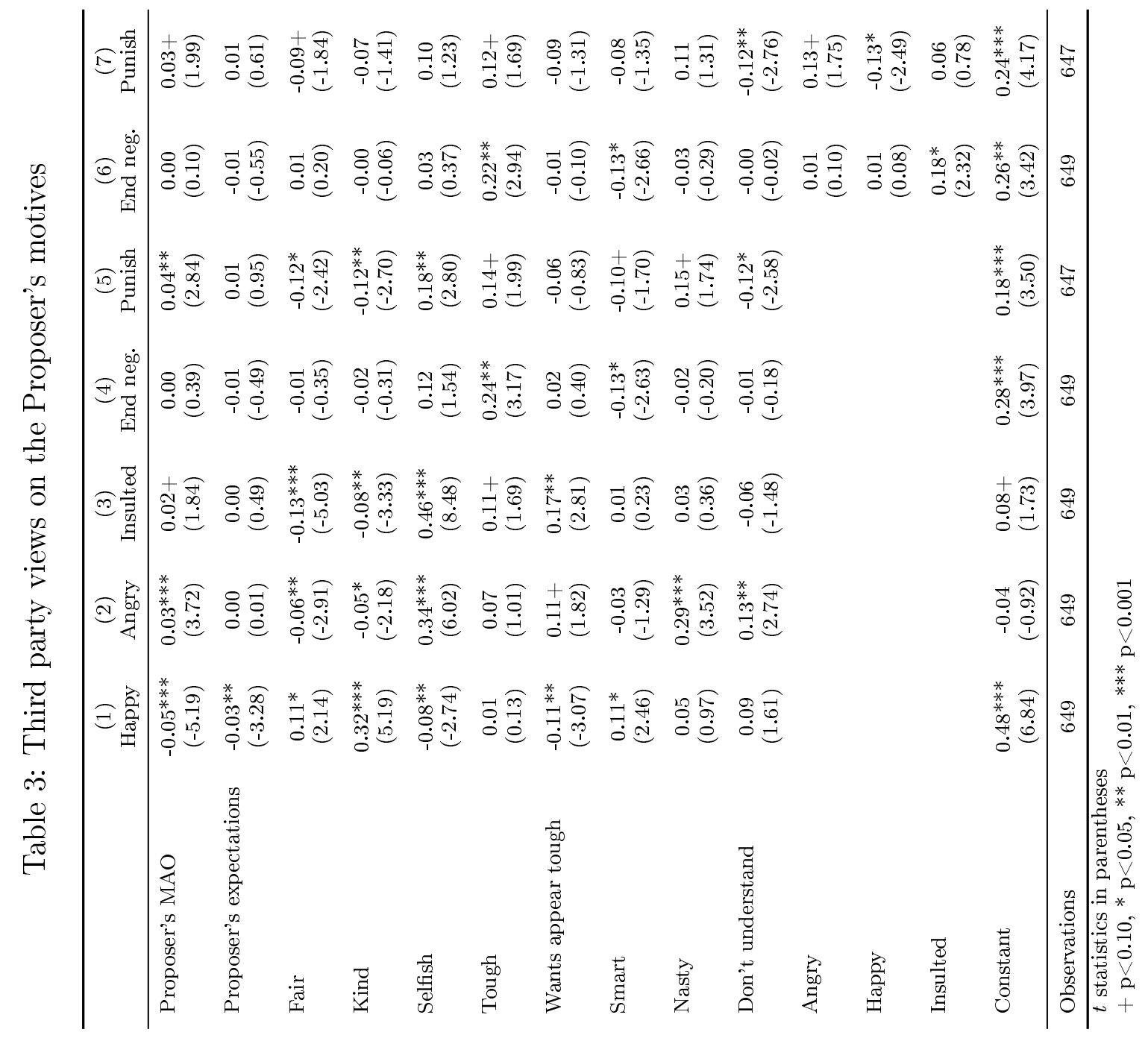


Taken together, these results suggest that preferences over intentions are driving the negative reaction to high offers from the Proposer. We observe strong negative emotional reactions for demanding offers $\left(\mathcal{O}_{P}^{1}>6\right)$ and a substantial propensity to punish the Proposer for such offers. The desire to punish is linked with the observers' perception of the Proposer's intention. The absence of a clear link between expectations $\left(\widetilde{\mathcal{O}}_{P, E O}^{R}\right)$, negative emotions, and punishing behaviour does not point strongly to an explanation relying on the positive/negative reciprocity models from psychological game theory. Alternative explications of intention-based preferences such as models where agents are spiteful against non-altruistic agents Levine (1998) or have a wounded pride when receiving low offers (Straub and Murnighan, 1995; Yamagishi et al., 2012) seem better able to account for the observed behavioural pattern.

\subsection{Intention-based preferences and Proposers' reaction to a rejection of their initial offer}

Our experimental design is focused on understanding the effect of first offers. But it also allows us to get a glimpse of how intention-based preferences can play a role along the sequence of offers and counter-offers. As indicated in Section 3.3, we found that in some cases Responders indicated an expected minimal acceptable amount above the Proposer's initial request. The data suggests that it is not due to a misunderstanding from Responders; they expect that the Proposer's final acceptance decision will not only depend on the level of the Responder's final offer but also on the Responder's decision to reject or not the first offer.

Overall, we observe that the Responder's belief about the minimal acceptable counter-offer is above the initial request in 17 percent of observations. A breakdown of the data shows that these cases are strictly concentrated in situations when the first offer was the equal split or below. It suggests that when a kind/fair first offer is rejected by the Responder he expects that the Proposer may end up asking more than the initial request to accept a counter-offer. Using our actual choice behaviour from Proposers, we can actually observe such a behaviour from Proposers. Several of them who asked an equal split, chose a minimal acceptable counter-offer above the equal split in case of rejection by the Responder. Table 


\begin{tabular}{|c|c|c|c|c|c|c|c|}
\hline Initial request from the Proposer & 0 & 1 & 2 & 3 & 4 & 5 & $>6$ \\
\hline \multicolumn{8}{|l|}{ Responders' beliefs higher than request } \\
\hline Proportion of Responders & $58 \%$ & $39 \%$ & $34 \%$ & $30 \%$ & $30 \%$ & $3 \%$ & $0 \%$ \\
\hline Expected minimal acceptable counter-offer & 3.3 & 4.2 & 4.8 & 5 & 5.1 & 7 & 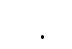 \\
\hline \multicolumn{8}{|c|}{ Proposer's minimal acceptable counter-offer higher than request } \\
\hline Proportion of Proposers doing so & . & . & 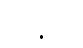 & . & $0 \%^{1}$ & $9 \%^{2}$ & $0 \%^{3}$ \\
\hline Average minimal acceptable counter-offer & 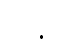 & . & 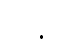 & 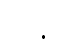 & . & 6.8 & . \\
\hline
\end{tabular}

Table 4: Cases where the minimal acceptable offer is above the initial request after a rejection from the Responder. Responders give an answers for all possible first offers from the Proposer. For the Proposer we compare their actual offer to the declared minimal acceptable counter-offer. ${ }^{1} 0$ Proposers out of 2 requesting $\$ 4,{ }^{2}$ 5 Proposers out of 55 who requested $\$ 5,{ }^{3} 0$ Proposer out of 22 requesting more than $\$ 6$.

4 presents the frequency of situations where Responders believe that Proposers may ask more after a rejection of the initial offer, and the situations where such a behaviour is observed from Proposers.

These observations suggests that a Proposer who made a kind/fair first offer may react negatively to it being rejected by the Responder. And that this behaviour is anticipated by Responders. Intuitively, refusing a kind gesture can be perceived as offensive in itself. Moreover, it may requalify the nature of the proposed deal. The Proposer may feel better about having wilfully granted more to the Responder than about the Responder having refused this gesture and offered back a take it or leave it offer for an amount still unequal. If players care about the respect showed through the offers, they can feel that they were denied a kind offer and rewarded with a patronising unequal split. Overall, while these cases are a minority, they support the picture emerging from the dynamics taking place with first offers. They also point to the fact that intention-based preferences will not only play a role in first offers, but all throughout the sequence of offers and counter-offers.

\subsection{What is a the profit-maximizing opening offer?}

Given that Responders will accept low requests $\left(\mathcal{O}_{P}^{1}\right)$ but punish requests which are too high above the equal split, an interesting side question is what is the "best" 
or rather most profitable opening offer for the Proposer. Figure 5 reveals that the highest final offer is, on average, made following requests slightly above the equal payoff split. The data from the third party observers give valuable insights into why it is the case. For each offer, the observers were asked how they would feel if faced with such an offer. While offers of 6 did not make the observer happy, they also did not make him angry. It is for offers of 6 that the observer thinks he would feel most neutral as a Responder.

Looking at the distribution of Responders' responses when faced with a request of 6 we observe that most of them make a counter-offer of 5 , a few of them accept the initial offer and a few of them make a punishing counter-offer. On aggregate, these responses to a request of 6 deliver an average payoff for the Proposer which is slightly higher than a request of 5 , though the difference is not significant $(p=0.31)$. While equal payoffs are most often accepted, they are also sometimes rejected to make place for a low counter-offer. Note that while 6 is the first offer with highest payoffs, it is associated with an expected final payoff of almost exactly 5 (Figure 5). Therefore, asking for an amount slightly above the equal payoff (fairness) split was a way to increase the chances of such an equal split in the end.

Result 7 (The optimal first offer requests slightly more than the equal split) A Proposer's maximal expected final offer was obtained for an initial request sligthly above the equal split.

\section{Discussion}

We have investigated the effect of opening offers on the outcome of a negotiation. We designed an alternating-offer bargaining game mimicking the typical start of a negotiation process, with one bargainer making an offer for a split of $\$ 10$, which the other bargainer can accept, or reject to make a counter-offer. This design allows us to observe how a bargainer receiving the opening offer in a negotiation reacts to it. While the Proposer's initial offer should not influence the final outcome under classical assumptions, we find that it nevertheless influences the Responder's behaviour with his average final offer being maximal for first offers close to the even payoff split and smaller both for lower and for higher offers from the Proposer. 
In line with the literature on bargaining with reputation (Abreu and Gul, 2000; Wolitzky, 2012; Embrey, Fréchette and Lehrer, 2014), we interpret this pattern as resulting from the informational effect of first offers. We observe that most Proposers ask for the equal payoff and that it is a credible signal of their willingness not to accept any lower amount as they set their minimum acceptable offer also at the equal payoff. Responders rightly react to Proposers' first offer and in most cases do not try to make a lower counter-offer when the first offer request is equal or below the equal payoff split. However, for offers requesting more than the equal split, Proposers are mostly willing to accept lower counter-offers. Responders accurately perceive that offers requesting more than the equal split do not signal a minimum acceptable amount. Though, such offers are not well received by Responders who tend to make punishing counter-offers. A survey from external observers indicate that offers requesting too much are perceived as likely to trigger the Responders' anger and unhappiness.

These results indicate that opening offers can send two different signals. Offers equal or below the equal split are informative about the Proposer's reservation value. They may therefore signal that the Proposer is obstinate and lead the Responder to accept the offer. Offers requesting more than the equal split are not credible signals of stubbornness. However, they can be interpreted as an unkind move from the Proposer. It often leads the Responder to react with spitefulness and therefore a smaller counter-offer.

A large body of economic research has shown that bargainers' distributional preferences play a substantial role in their decision to accept a deal or not. This study adds to this evidence by showing that another type of social preferences, intention-based preferences, also play a role. As a consequence, the success or failure of a negotiation does not only depend on the final offer on the table but also on the emerging dynamics of the bargaining process. The intermediary offers made during a negotiation can be interpreted by the other bargainer as suggesting either kind and compromising intentions, or unkind and uncompromising ones. And the perception of such intentions can, in turn, influence the final outcome of the bargaining process. For this reason, as suggested by the quote of Raiffa in a classical book on negotiation at the beginning of this article, it is not the best strategy to always be as tough as possible in a negotiation. 
Our findings nicely unite two conflicting views in the existing psychological literature on first offers in negotiations. On one side, it is argued that a demanding opening offer results in a higher individual outcome because it works as an anchor: Tversky and Kahneman (1974) have shown that an initial salient piece of information is used to make subsequent judgements. And because behavioural adjustments tend to be insufficient, irrespective of the level of the anchor, demanding opening offers bias the final outcome in the direction of the offer (Galinsky and Mussweiler, 2001). The second view suggests that bargainers initiating the negotiation with a reasonable offer achieve the more favourable outcomes because extremely demanding opening offers may sour the atmosphere and endanger the agreement (Raiffa, 1982). We find support for both hypotheses: the highest bargaining outcome is not obtained for a first offer requesting the equal split, but for a slightly higher request which increases the chances to get the equal split or above. It is because there is a small window above the equal split where offers do not trigger negative emotions. We conjecture that Responders consider it "fair game" to start the negotiation just above a good bargaining compromise (here the equal split).

The role played by intention-based preferences in bargaining suggests that striking a good bargain is a balancing act requiring not to be too soft (as it is not often rewarded) and not too tough (as it is often punished). The field of Negotiation, taught in Business degrees, investigates the role of soft skills in negotiations: It asks how the interaction process during the negotiation can be used to enhance the likelihood to reach a successful agreement. The present research suggests that economists can meaningfully venture into this aspect of economic behaviour using inter alia the insights of models of intention-based preferences as well as reputation with stubborn types.

\section{References}

Abreu, Dilip, and Faruk Gul. 2000. "Bargaining and reputation." Econometrica, 68(1): 85-117.

Anbarci, Nejat, Nick Feltovich, and Mehmet Y Gürdal. 2015. "Lying about 
the price? Ultimatum bargaining with messages and imperfectly observed offers." Journal of Economic Behavior \&S Organization, 116: 346-360.

Andersson, Ola, Matteo M Galizzi, Tim Hoppe, Sebastian Kranz, Karen Van Der Wiel, and Erik Wengström. 2010. "Persuasion in experimental ultimatum games." Economics Letters, 108(1): 16-18.

Bellemare, Charles, Alexander Sebald, and Martin Strobel. 2011. "Measuring the willingness to pay to avoid guilt: estimation using equilibrium and stated belief models." Journal of Applied Econometrics, 26(3): 437-453.

Bénabou, Roland, and Jean Tirole. 2006. "Incentives and Prosocial Behavior." The American Economic Review, 96(5): 1652-1678.

Besley, Timothy, and Maitreesh Ghatak. 2008. "Status incentives." The American Economic Review, 98(2): 206-211.

Blount, Sally. 1995. "When Social Outcomes Aren't Fair: The Effect of Causal Attributions on Preferences." Organizational Behavior and Human Decision Processes, 63(2): 131-144.

Bolton, Gary E, and Axel Ockenfels. 2000. "ERC: A theory of equity, reciprocity, and competition." American Economic Review, 166-193.

Brandts, Jordi, and Gary Charness. 2011. "The strategy versus the directresponse method: a first survey of experimental comparisons." Experimental Economics, 14(3): 375-398.

Burnham, Terence C. 2007. "High-testosterone men reject low ultimatum game offers." Proceedings of the Royal Society of London B: Biological Sciences, 274(1623): 2327-2330.

Camerer, Colin. 2003. Behavioral game theory: Experiments in strategic interaction. Princeton University Press.

Charness, Gary, and Matthew Rabin. 2002. "Understanding social preferences with simple tests." Quarterly Journal of Economics, 117(3): 817-869.

Charness, Gary, David Masclet, and Marie Claire Villeval. 2010. "Competitive preferences and status as an incentive: Experimental evidence." Groupe d'Analyse et de Théorie Economique working paper, , (1016).

Crawford, Vincent P, and Joel Sobel. 1982. "Strategic information transmission." Econometrica: Journal of the Econometric Society, 1431-1451. 
Croson, Rachel, Terry Boles, and J Keith Murnighan. 2003. "Cheap talk in bargaining experiments: lying and threats in ultimatum games." Journal of Economic Behavior \&f Organization, 51(2): 143-159.

Dufwenberg, Martin, and Georg Kirchsteiger. 2004. "A theory of sequential reciprocity." Games and Economic Behavior, 47(2): 268-298.

Dufwenberg, Martin, Simon Gächter, and Heike Hennig-Schmidt. 2011. "The framing of games and the psychology of play." Games and Economic Behavior, $73(2)$ : 459-478.

Ellingsen, Tore, and Magnus Johannesson. 2008. "Pride and Prejudice: The Human Side of Incentive Theory." American Economic Review, 98(3): 990-1008.

Embrey, Matthew, Guillaume R Fréchette, and Steven F Lehrer. 2014. "Bargaining and Reputation: An Experiment on Bargaining in the Presence of Behavioural Types." The Review of Economic Studies, rdu029.

Eriksson, Tor, and Marie Claire Villeval. 2012. "Respect and relational contracts." Journal of Economic Behavior \& Organization, 81(1): 286-298.

Falk, Armin, and Urs Fischbacher. 2006. "A theory of reciprocity." Games and Economic Behavior, 54(2): 293-315.

Falk, Armin, Ernst Fehr, and Urs Fischbacher. 2003. "On the nature of fair behavior." Economic Inquiry, 41(1): 20-26.

Fehr, Ernst, and Klaus M Schmidt. 1999. "A theory of fairness, competition, and cooperation." Quarterly Journal of Economics, 114(3): 817-868.

Galinsky, Adam D, and Thomas Mussweiler. 2001. "First offers as anchors: the role of perspective-taking and negotiator focus." Journal of Personality and Social Psychology, 81(4): 657.

Goldreich, David, and Eukasz Pomorski. 2011. "Initiating Bargaining." The Review of Economic Studies, 78(4): 1299-1328.

Greiner, Ben. 2015. "Subject pool recruitment procedures: organizing experiments with ORSEE." Journal of the Economic Science Association, 1(1): 114125.

Heffetz, Ori, and Robert H Frank. 2008. "Preferences for status: Evidence and economic implications." Handbook of Social Economics, Jess Benhabib, Alberto Bisin, Matthew Jackson, eds, 1: 69-91. 
Hurley, Terrance M, and Jason F Shogren. 2005. "An experimental comparison of induced and elicited beliefs." Journal of Risk and Uncertainty, 30(2): 169188.

Kriss, Peter H, Rosemarie Nagel, and Roberto A Weber. 2013. "Implicit vs. explicit deception in ultimatum games with incomplete information." Journal of Economic Behavior \& Organization, 93: 337-346.

Levine, David K. 1998. "Modeling altruism and spitefulness in experiments." Review of Economic Dynamics, 1(3): 593-622.

Nash, John. 1953. "Two-person cooperative games." Econometrica: Journal of the Econometric Society, 128-140.

Offerman, Theo. 2002. "Hurting hurts more than helping helps." European Economic Review, 46(8): 1423-1437.

Rabin, Matthew. 1993. "Incorporating fairness into game theory and economics." American Economic Review, 1281-1302.

Raiffa, Howard. 1982. The art and science of negotiation. Harvard University Press.

Raiffa, Howard, John Richardson, and David Metcalfe. 2002. Negotiation analysis: the science and art of collaborative decision making. Harvard University Press.

Rankin, Frederick W. 2003. "Communication in ultimatum games." Economics Letters, 81(2): 267-271.

Roth, Alvin E. 1995. "The handbook of experimental economics." In . , ed. John H Kagel, Alvin E Roth and John D Hey, Chapter Bargaining experiments. Princeton university press Princeton, NJ.

Rubinstein, Ariel. 1982. "Perfect equilibrium in a bargaining model." Econometrica, 97-109.

Schaffner, Markus. 2013. "Programming for experimental economics: Introducing coralŮa lightweight framework for experimental economic experiments." QUT Business School.

Ståhl, I. 1972. Bargaining Theory. (Ekonomiska forskningsinstitutet vid Handelshögskolan i Stockholm (EFI)). 
Straub, Paul G, and J Keith Murnighan. 1995. "An experimental investigation of ultimatum games: Information, fairness, expectations, and lowest acceptable offers." Journal of Economic Behavior \& Organization, 27(3): 345364.

Tingley, Dustin H, and Barbara F Walter. 2011. "Can cheap talk deter? An experimental analysis." Journal of Conflict Resolution, 55(6): 996-1020.

Tversky, Amos, and Daniel Kahneman. 1974. "Judgment under uncertainty: Heuristics and biases." Science, 185(4157): 1124-1131.

Wilcox, Nathaniel T, and Nick Feltovich. 2000. "Thinking like a game theorist: Comment." University of Houston Department of Economics working paper.

Wolitzky, Alexander. 2012. "Reputational bargaining with minimal knowledge of rationality." Econometrica, 80(5): 2047-2087.

Xiao, Erte, and Daniel Houser. 2005. "Emotion expression in human punishment behavior." Proceedings of the National Academy of Sciences of the United States of America, 102(20): 7398-7401.

Yamagishi, Toshio, Yutaka Horita, Nobuhiro Mifune, Hirofumi Hashimoto, Yang Li, Mizuho Shinada, Arisa Miura, Keigo Inukai, Haruto Takagishi, and Dora Simunovic. 2012. "Rejection of unfair offers in the ultimatum game is no evidence of strong reciprocity." Proceedings of the National Academy of Sciences, 109(50): 20364-20368.

Zizzo, Daniel John. 2010. "Experimenter demand effects in economic experiments." Experimental Economics, 13(1): 75-98. 


\section{A Instructions}

General Instructions

\section{General Remarks}

Thank you for participating in this experiment on decision-making. During the experiment you and the other participants are asked to make a series of decisions. The money you will earn will depend partly on your own choices and partly on the choices of other participants. All payments will be made confidentially and in cash at the end of the experiment. Please consider all expressions as gender neutral.

Please do not communicate with other participants. If you have any questions after we finish reading the instructions please raise your hand and an experimenter will approach you and answer your question in private.

\section{Roles}

There are two roles in this experiment: Player A and Player B. At the start of the experiment you will be assigned to one of these two roles through a randomized procedure. Your role will then remain the same throughout the experiment. Your role will only be known to you. Each Player A will be randomly paired with one Player B. No one will ever be informed about the identity of the participant you were paired with nor will anybody else be informed about the choices you made.

\section{Earnings}

You will receive $\$ 3$ for participating in this experiment. Depending on your decisions and the decisions of other participants you will receive an additional amount according to the rules explained below.

\section{Privacy}

This experiment is designed such that nobody, including the experimenters and the other participants, will ever be informed about the choices you or anyone else will make in the experiment. Neither your name nor your student ID will appear on any decision form. The only identifying label will be a number that is known only to you. At the end of the experiment, you are asked one-by-one to collect your earnings in an envelope from a person who has no involvement in and no information about the experiment. 


\section{The Game}

In this experiment, you play with one other participant. Each Player A will be randomly paired with one Player B. Each A/B pair can divide an amount of \$10 among themselves.

1. Player A proposes how he thinks the $\$ 10$ should be divided between him and Player B.

2. Player B can then either "accept" or "reject" Player A's proposition.

o If he accepts, both players will receive an amount according to Player A's suggested partition.

o If he rejects Player A's proposition, Player B makes a counteroffer regarding the split of the $\$ 10$ between him and Player $A$.

3. If Player B has rejected and made his counteroffer, Player A can either "accept" or "reject" the partition of the $\$ 10$ that is proposed to him by Player $\mathrm{B}$.

o If Player A accepts, both players will receive an amount according to Player B's suggested partition.

o If Player A rejects, both players earn nothing.

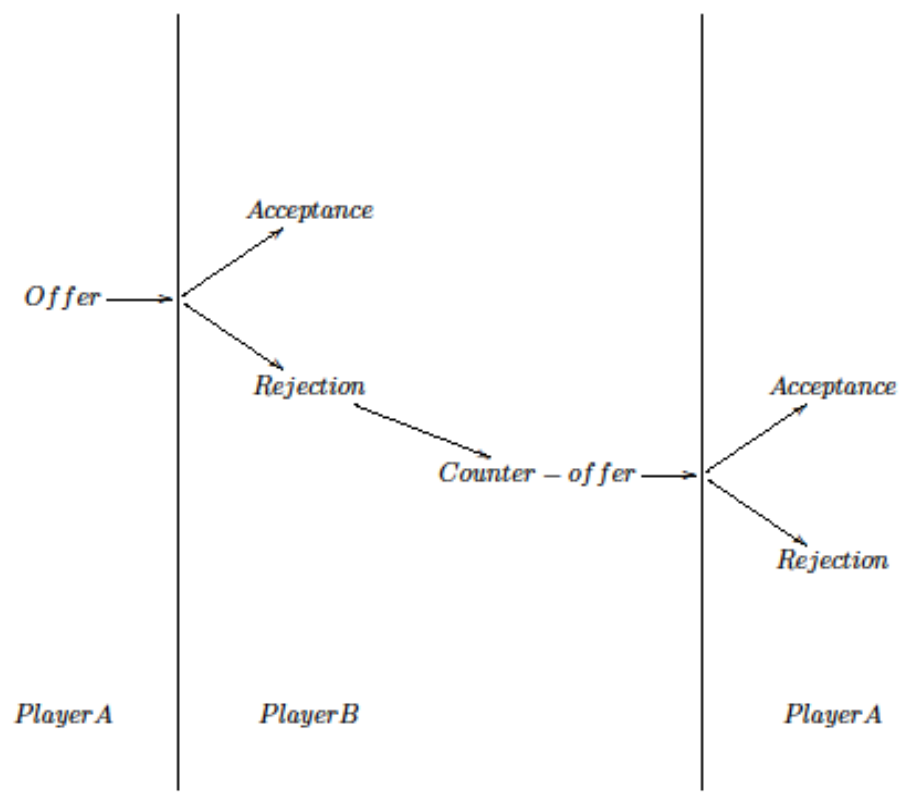




\section{Decision Tasks}

\section{Decision Task - Player A}

If you are assigned the role of Player A, you will make two decisions:

1. You are asked to make a proposition on how much of the $\$ 10$ you want to keep for yourself. You can keep any amount between $\$ 0$ and $\$ 10$. The rest (if any) will be offered to Player $B$.

2. You will not be informed whether Player B accepts or rejects your proposition before the end of the experiment. You are therefore asked to state the minimum amount you would need to receive in a counteroffer to just accept it. This means that you would accept all counteroffers above or equal to this amount and reject all below it.

\section{Decision Task - Player B}

If you are assigned the role of Player B, you are asked to decide whether you accept or reject Player A's offer regarding the split of the $\$ 10$.

If you reject his offer, you are asked to make a counteroffer as to how you think the $\$ 10$ should be divided. In your counteroffer, you can keep any amount between $\$ 0$ and $\$ 10$. The rest (if any) will be offered to Player A.

During the experiment you will not be informed about Player A's actual offer. You therefore make all your choices for each possible offer from Player A.

\section{Earnings}

At the end of the experiment the cash payments are determined for each pair of participants:

\begin{tabular}{|c|c|c|c|}
\hline & & $\begin{array}{c}\text { Payoff } \\
\text { Player A }\end{array}$ & $\begin{array}{c}\text { Payoff } \\
\text { Player B }\end{array}$ \\
\hline a) B accepts A's offer of $\$ X$ & & $\$ 10-\$ X$ & $\$ X$ \\
\hline b) B rejects A's offer of $\$ X$ and & $\begin{array}{l}\text { - B's counteroffer of } \$ Y \text { for } A \text { is bigger than (or } \\
\text { equal to) A's minimum amount to accept } \\
\text { - B's counteroffer of } \$ Y \text { for } A \text { is smaller than } \\
\text { A's minimum amount to accept }\end{array}$ & $\begin{array}{l}\$ Y \\
\$ 0\end{array}$ & $\begin{array}{l}\$ 10-\$ Y \\
\$ 0\end{array}$ \\
\hline
\end{tabular}




\section{Instructions - Part II}

We ask you now to guess some of the answers the other player gave or is about to give. You can earn additional money for your guesses if they are correct.

\section{Player A -- Tasks}

If you were assigned the role of Player A, we ask you to guess if Player B will accept or reject your offer for all offers that you could have made. In case you think he will reject it, we also ask you to guess how much Player B will offer you in his counteroffer.

\section{Player B -- Tasks}

If you were assigned the role of Player B, we ask you to make two guesses about answers Player A gave or is about to give:

1. We asked Player $A$ to guess your reaction to his proposed split of the $\$ 10$. We now ask you to guess how Player A thinks you would react for each of his potential partition propositions: If Player A offered you \$X, does he expect you to accept his offer? And if you think he does not expect you to accept it, how much does he think you will offer him in your counteroffer?

2. Suppose you rejected Player A's proposition. We ask you to guess how much you have to give at least to Player $A$ in your counteroffer so that he still accepts it. This means that you would expect Player A to accept all of your counteroffers, in which you give him more than $\$ X$, and to reject all of your counteroffers, in which you give him less than $\$ X$. We ask you to make a guess about $\$ X$ for each of Player A's initial offers.

\section{Earnings}

You can earn additional money if your stated guesses match the actual answers given by the other player: You earn $\mathbf{\$ 0 . 5 0}$ for every correct guess.

- Player A: You receive an additional $\$ 0.50$ for each correct belief about Player B's acceptance decision. In case you correctly guess that Player B rejects your offer, you earn extra $\$ 0.50$ if your guess about Player B's counteroffer coincides with his actual offer.

- Player B: You receive additional money if your guess about Player A's expectation of your reaction matches his actual expectation. Here you can earn $\$ 0.50$ for each correct guess on whether Player A expects you to accept his offer and in case of a correctly expected rejection you receive $\$ 0.50$ for each correct guess about what he expects you to counteroffer him.

Furthermore, you earn an additional $\$ 0.50$ for each correct guess about Player A's smallest accepted counteroffer. 
B Screenshots from the experiment 


\section{Screenshots - Player A (Proposer)}

\section{General Instructions}

\section{General Remarks}

Thank you for participating in this experiment on decision-making. During the experiment you and the other participants are asked to make a series of decisions. The money you will earn will depend partly on your own choices and partly on the choices of other participants. All payments will be made confidentially and in cash at the end of the experiment. Please consider all expressions as gender neutral.

Please do not communicate with other participants. If you have any questions after we finish reading the instructions please raise your hand and an experimenter will approach you and answer your question in private.

\section{Roles}

There are two roles in this experiment: Player A and Player B. At the start of the experiment you will be assigned to one of these two roles through a randomized procedure Your role will then remain the same throughout the experiment. Your role will only be known to you. Each Player A will be randomly paired with one Player B. No one will ever be informed about the identity of the participant you were paired with nor will anybody else be informed about the choices you made.

\section{Earnings}

You will receive $\$ 3$ for participating in this experiment. Depending on your decisions and the decisions of other participants you will receive an additional amount according to the rules explained below

\section{Privacy}

This experiment is designed such that nobody, including the experimenters and the other participants, will ever be informed about the choices you or anyone else will make in the experiment. Neither your name nor your student ID will appear on any decision form. The only identifying label will be a number that is known only to you. At the end of the experiment, you are asked one-by-one to collect your earnings in an envelope from a person who has no involvement in and no information about the experiment. 


\section{The Game}

In this experiment, you play with one other participant. Each Player A will be randomly paired with one Player B. Each A/B pair can divide an amount of $\$ 10$ among themselves.

1. Player A proposes how he thinks the $\$ 10$ should be divided between him and Player $B$.

2. Player B can then either "accept" or "reject" Player A's proposition.

- If he accepts, both players will receive an amount according to Player A's suggested partition

- If he rejects Player A's proposition, Player B makes a counteroffer regarding the split of the $\$ 10$ between him and

Player A

3. If Player B has rejected and made his counteroffer, Player A can either "accept" or "reject" the partition of the $\$ 10$ that is proposed to him by Player B.

- If Player A accepts, both players will receive an amount according to Player B's suggested partition.

- If Player A rejects, both players earn nothing.

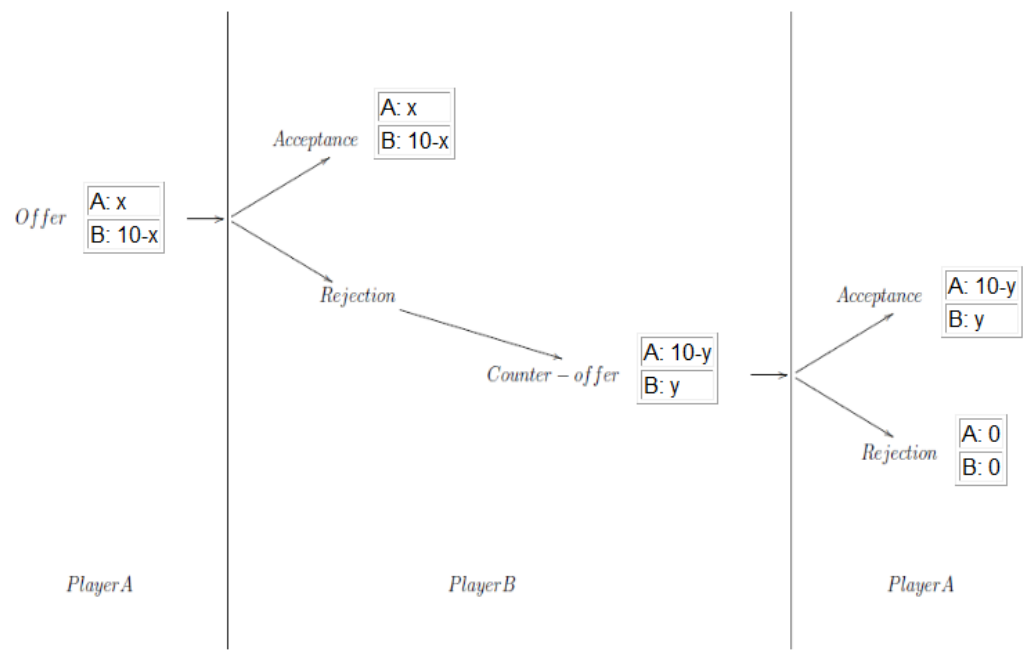

Practice Question

1. Suppose Player A's offer was rejected by Player B. In his subsequent counteroffer, Player B offers an amount of \$y to Player A. Player A said he rejects all counteroffers below \$z. The counteroffer of \$y is smaller than A's minimum amount to accept: \$y

How much would Player A earn?

How much would Player B earn? 


\section{Practice Question}

2. Suppose now Player A decided to keep $\$ 10$-x for himself and to offer $\$ x$ to Player B. Furthermore, he said he rejects all counteroffers below \$z. Player B accepted Player A's proposition.

How much would Player A earn?

How much would Player B earn?

You are

Player A 


\section{Player A}

Please make a proposition how you want to split the $\$ 10$ between Player B and yourself. Please decide how much you want to keep for yourself . Player B will then be offered 10 minus your choice. You can insert any integer number from 0 to 10 .

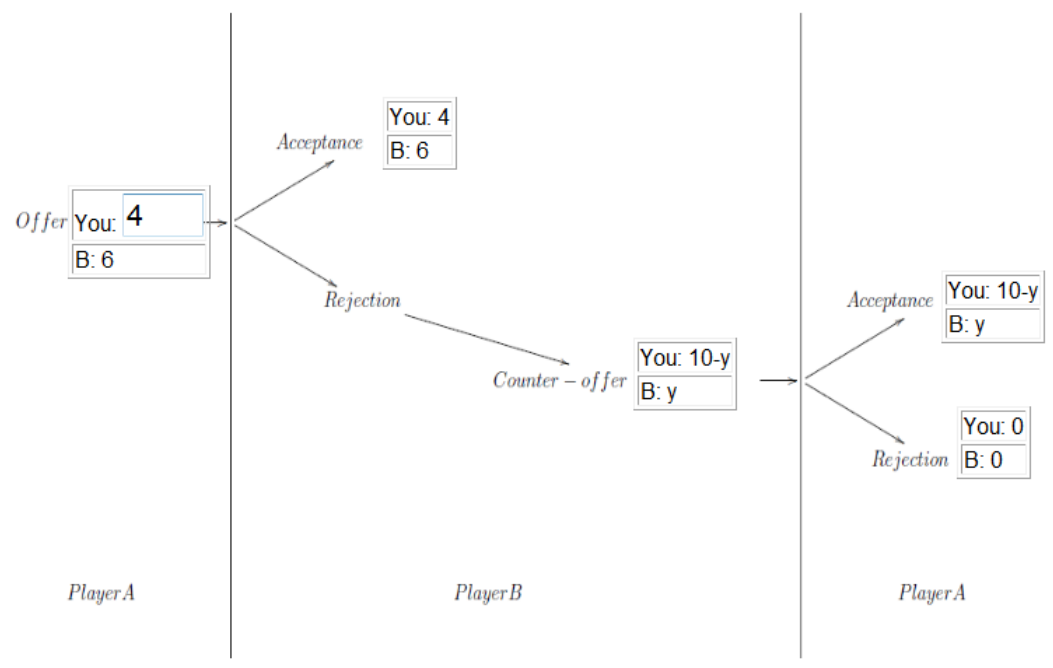

\section{Player A}

Suppose Player B rejected your proposition and proposes a counteroffer. What is the minimum amount Player B has to offer you so that you just accept his proposal? This means that you accept all counteroffers above or equal to this amount and reject all below it. You can insert any integer number from 0 to 10.

I reject all counteroffers below $\$ 4$ 


\section{WAIT}

Please wait until the experiment continues.

Instructions - Part II

We ask you now to guess some of the answers the other player gave or is about to give. You can earn additional money for your guesses if they are correct.

\section{Player A -- Tasks}

If you were assigned the role of Player A, we ask you to guess if Player B will accept or reject your offer for all offers that you could have made. In case you think he will reject it, we also ask you to guess how much Player B will offer you in his counteroffer

\section{Player B -- Tasks}

If you were assigned the role of Player B, we ask you to make two guesses about answers Player A gave or is about to give:

1. We asked Player $\mathbf{A}$ to guess your reaction to his proposed split of the $\$ 10$. We now ask you to guess how Player $\mathbf{A}$ thinks you would react for each of his potential partition propositions: If Player $A$ offered you $\$ X$, does he expect you to accept his offer? And if you think he does not expect you to accept it, how much does he think you will offer him in your counteroffer?

2. Suppose you rejected Player A's proposition. We ask you to guess how much you have to give at least to Player $\mathbf{A}$ in your counteroffer so that he still accepts it. This means that you would expect Player $A$ to accept all of your counteroffers, in which you give him more than $\$ X$ and to reject all of your counteroffers, in which you give him less than $\$ X$. We ask you to make a guess about $\$ X$ for each of Player A's initial offers.

\section{Earnings}

You can earn additional money if your stated guesses match the actual answers given by the other player: You earn $\$ 0.50$ for every correct guess.

- Player A: You receive an additional $\$ 0.50$ for each correct belief about Player B's acceptance decision. In case you correctly guess that Player B rejects your offer, you earn extra $\$ 0.50$ if your guess about Player B's counteroffer coincides with his actual offer

- Player B: You receive additional money if your guess about Player A's expectation of your reaction matches his actual expectation. Here you can earn $\$ 0.50$ for each correct guess on whether Player A expects you to accept his offer and in case of a correctly expected rejection you receive $\$ 0.50$ for each correct guess about what he expects you to counteroffer him.

Furthermore, you earn an additional $\$ 0.50$ for each correct guess about Player A's smallest accepted counteroffer.

Suppose your proposition was to keep $\$ X$ for yourself and to offer $\$ 10-X$ to Player B. Suppose further that you guessed that Player B will reject this proposition and that he will make a counteroffer, in which he offers $\$ Y$ to you. Assume Player B indeed rejected such a proposition and made a counteroffer, in which you would get $\$ Z$.

How much do you earn for your guess? 


\section{Player A}

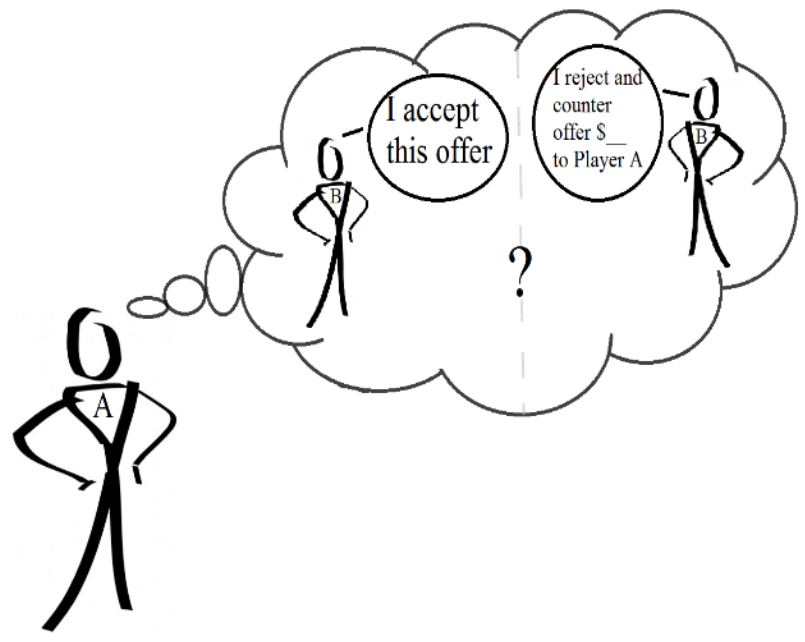

Please guess whether Player B accepts or rejects your offer. In the following, you are asked to make this guess for each offer you could have made. In case you think Player B rejects, we will also ask you to guess how much Player B will counteroffer you.

Next

\section{Player A}

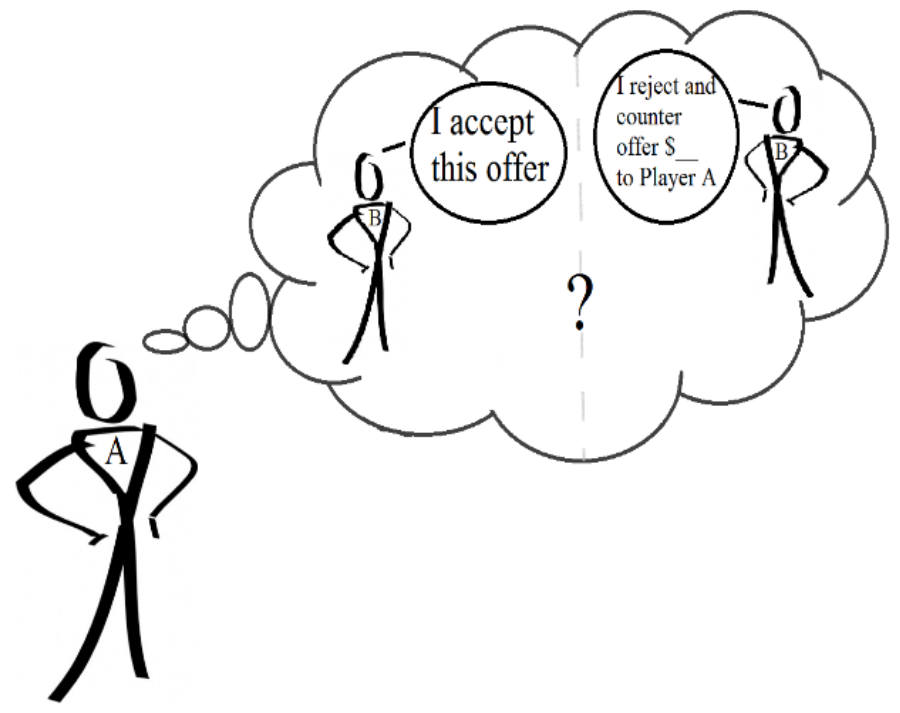

Suppose you chose to keep 2 for yourself and to offer 8 to Player B.

Do you think Player B accepts or rejects this proposition? 


\section{Player A}

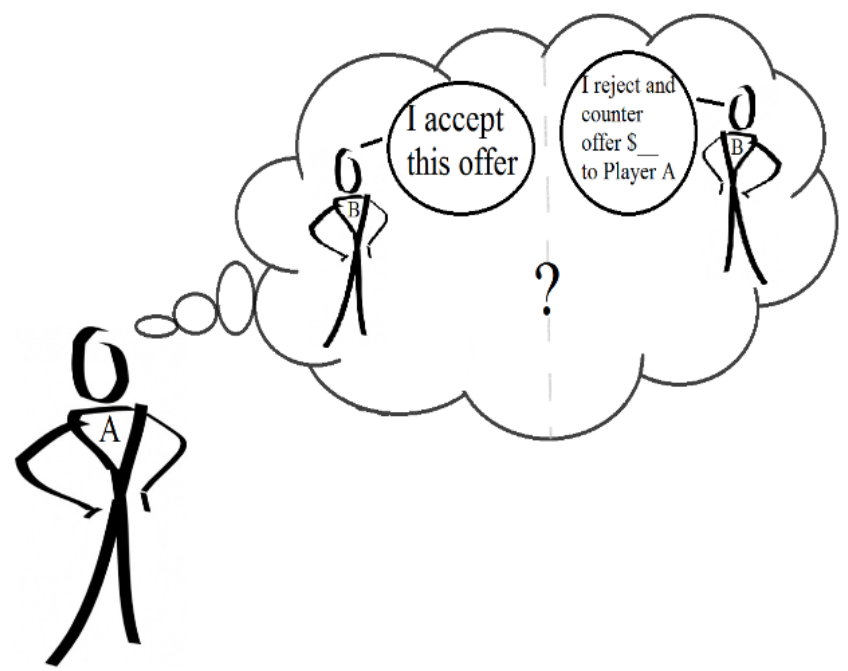

You have just said you believe Player B rejects a proposition in which you keep $\mathbf{2}$ for yourself and give $\mathbf{8}$ to Player B. How much do you think he will counteroffer you?

I think in Player B's counteroffer, I will get of the $\$ 10$. 


\section{Player A}

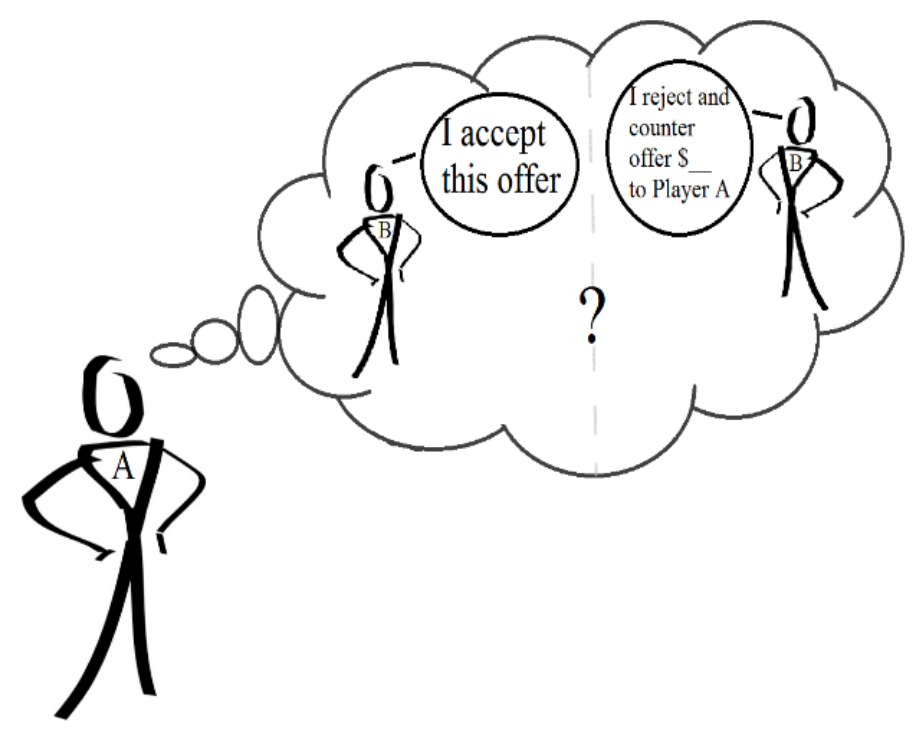

Suppose you chose to keep 5 for yourself and to offer 5 to Player B.

Do you think Player B accepts or rejects this proposition?

\begin{tabular}{l|l} 
Accept & Reject \\
\hline
\end{tabular}

\section{Player A}

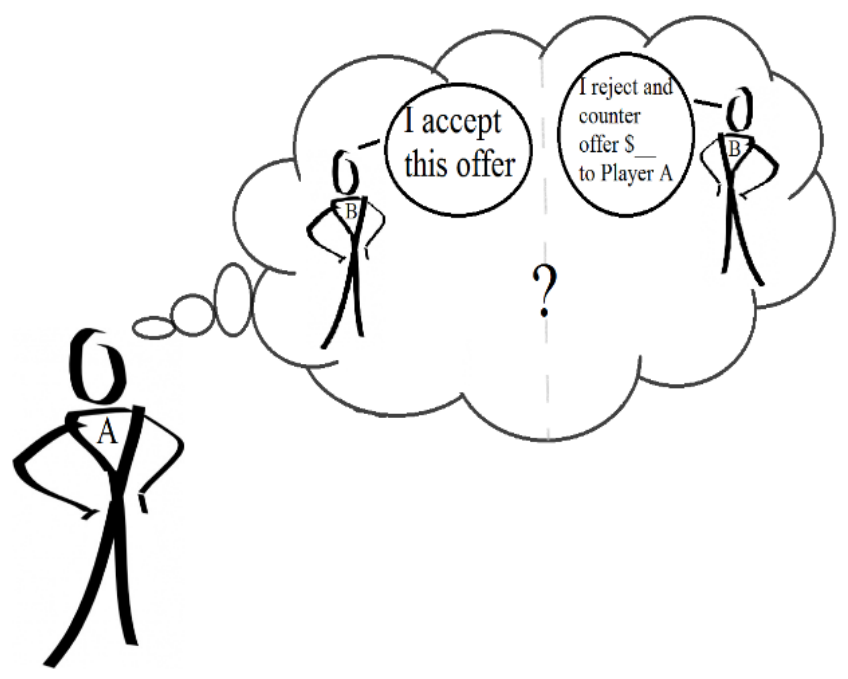

You just said you believe Player B accepts a proposition in which you keep $\mathbf{5}$ for yourself and give $\mathbf{5}$ to Player B. 
Now, we will ask you a few general questions. Please answer truthfully, nobody will be able to attribute your answers to you as we will keep them completely anony mous.

\begin{tabular}{|l|l|l|l|}
\hline Your gender & \begin{tabular}{|l|l|}
\hline Your age \\
\hline How often have you participated in experiments?
\end{tabular} \\
\hline How many other participants in this experiment \\
(in this room) do you know personally?
\end{tabular}




\section{Screenshots - Player B (Responder)}

\section{General Instructions}

\section{General Remarks}

Thank you for participating in this experiment on decision-making. During the experiment you and the other participants are asked to make a series of decisions. The money you will earn will depend partly on your own choices and partly on the choices of other participants. All payments will be made confidentially and in cash at the end of the experiment. Please consider all expressions as gender neutral

Please do not communicate with other participants. If you have any questions after we finish reading the instructions please raise your hand and an experimenter will approach you and answer your question in private.

\section{Roles}

There are two roles in this experiment: Player A and Player $\mathbf{B}$. At the start of the experiment you will be assigned to one of these two roles through a randomized procedure Your role will then remain the same throughout the experiment. Your role will only be known to you. Each Player A will be randomly paired with one Player B. No one will ever be informed about the identity of the participant you were paired with nor will anybody else be informed about the choices you made.

\section{Earnings}

You will receive $\$ 3$ for participating in this experiment. Depending on your decisions and the decisions of other participants you will receive an additional amount according to the rules explained below.

\section{Privacy}

This experiment is designed such that nobody, including the experimenters and the other participants, will ever be informed about the choices you or anyone else will make in the experiment. Neither your name nor your student ID will appear on any decision form. The only identifying label will be a number that is known only to you. At the end of the experiment, you are asked one-by-one to collect your earnings in an envelope from a person who has no involvement in and no information about the experiment. 


\section{The Game}

In this experiment, you play with one other participant. Each Player A will be randomly paired with one Player B. Each A/B pair can divide an amount of $\$ 10$ among themselves.

1. Player A proposes how he thinks the $\$ 10$ should be divided between him and Player $B$.

2. Player B can then either "accept" or "reject" Player A's proposition.

- If he accepts, both players will receive an amount according to Player A's suggested partition

- If he rejects Player A's proposition, Player B makes a counteroffer regarding the split of the $\$ 10$ between him and

Player A

3. If Player B has rejected and made his counteroffer, Player A can either "accept" or "reject" the partition of the $\$ 10$ that is proposed to him by Player B.

- If Player A accepts, both players will receive an amount according to Player B's suggested partition.

- If Player A rejects, both players earn nothing.

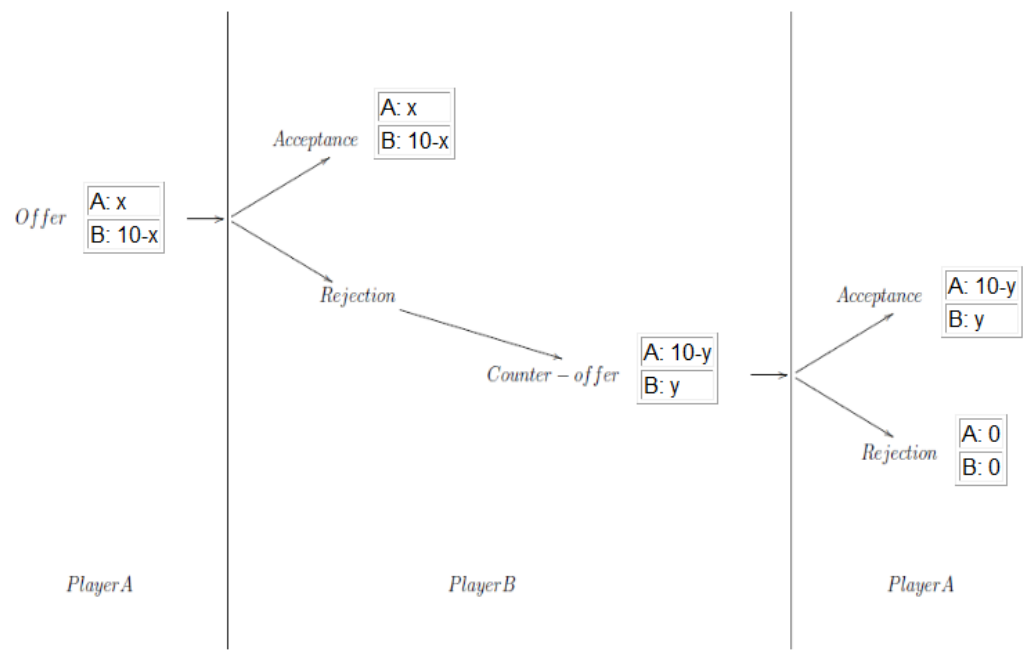

Practice Question

1. Suppose Player A's offer was rejected by Player B. In his subsequent counteroffer, Player B offers an amount of \$y to Player A. Player A said he rejects all counteroffers below \$z. The counteroffer of \$y is smaller than A's minimum amount to accept: \$y

How much would Player A earn?

How much would Player B earn? 


\section{Practice Question}

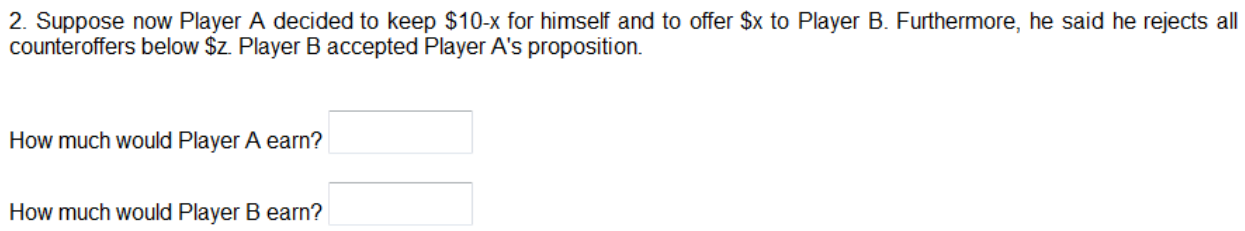

Next

\section{Your Role}

You are

Player B 


\section{Player B}

Please decide for each possible offer from Player A (called " $x$ " in the following picture) whether you accept or reject his proposition regarding the split of the $\$ 10$. If you decide to reject an offer, we will ask you to propose a counteroffer (called "y" in the picture) on how you want to split the $\$ 10$

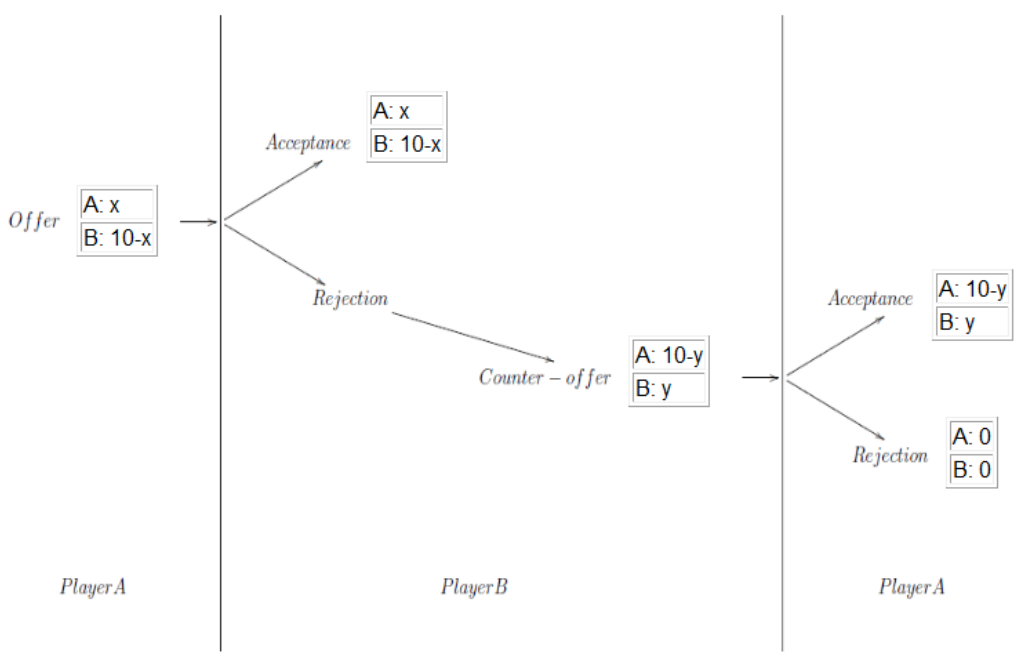

\section{Player B}

Suppose Player A wants to keep 10 for himself and offers you 0 .

Do you accept this offer or do you want to reject to make a counter proposal? Please click either on the blue accept or reject button.

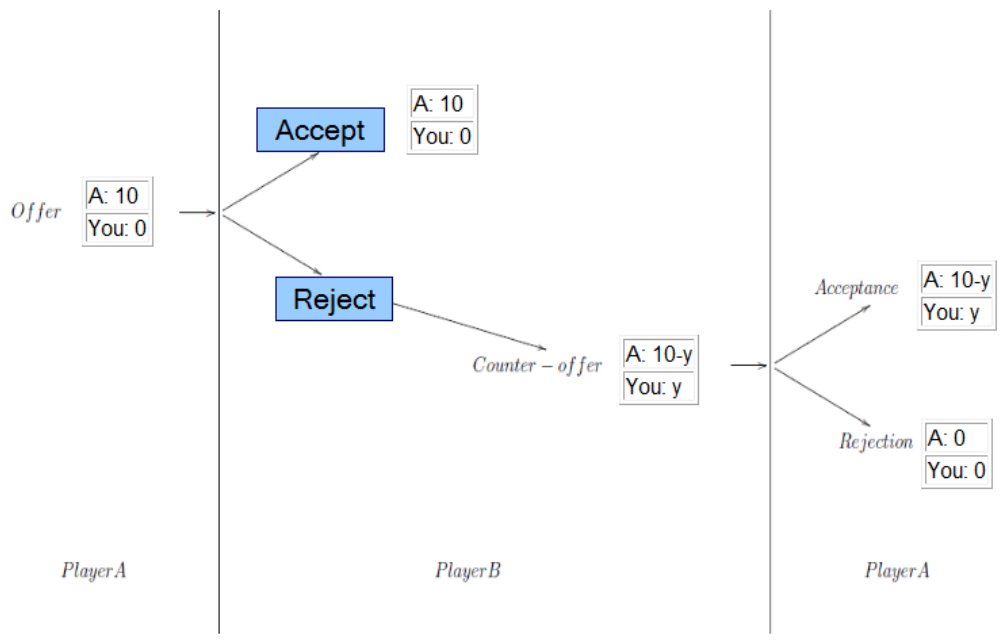




\section{Player B}

You have accepted an offer of 0 .

Next

\section{Player B}

Suppose Player A wants to keep 9 for himself and offers you 1

Do you accept this offer or do you want to reject to make a counter proposal? Please click either on the blue accept or reject button.

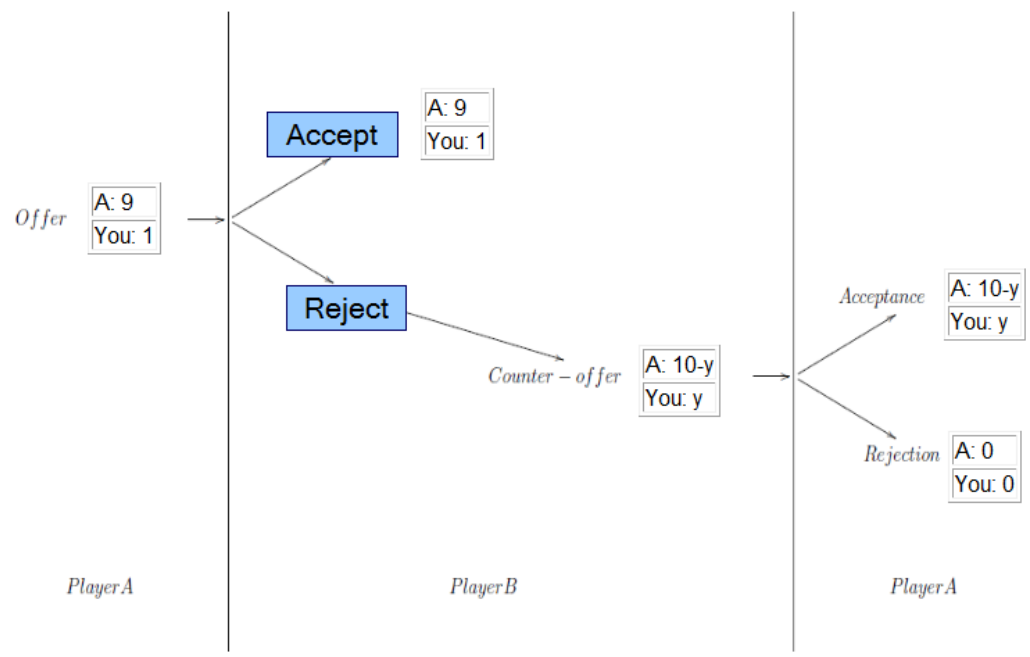




\section{Player B}

You have rejected an offer of 1 .

Please make a counter proposal to Player A by deciding how much of the $\$ 10$ you want to keep for yourself. Player B will then be offered $\$ 10$ minus your choice. You can insert any integer number from 0 to 10 .

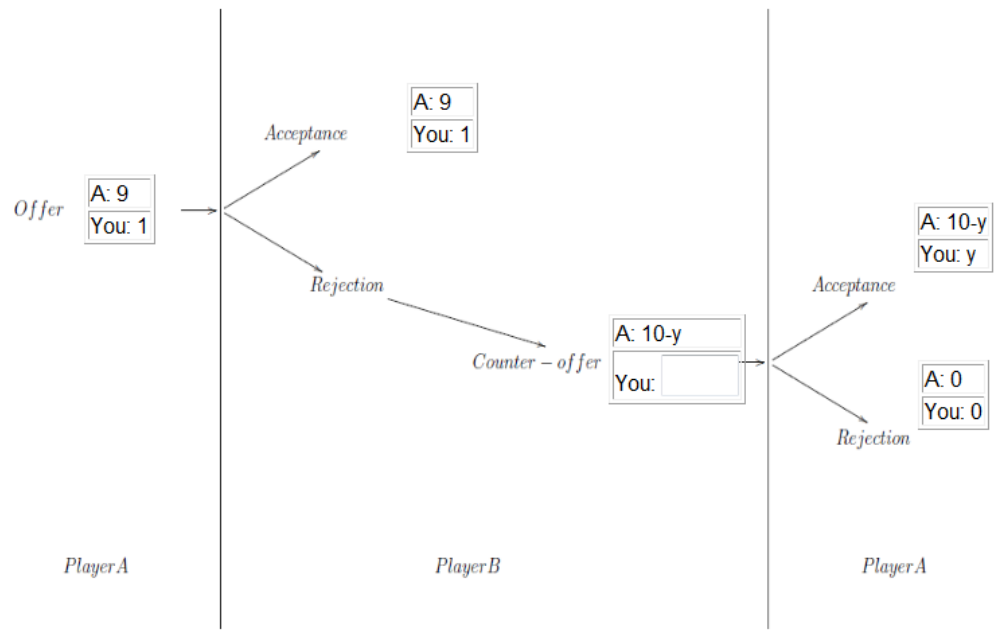

\section{Player B}

Suppose Player A wants to keep 2 for himself and offers you 8 .

Do you accept this offer or do you want to reject to make a counter proposal? Please click either on the blue accept or reject button.

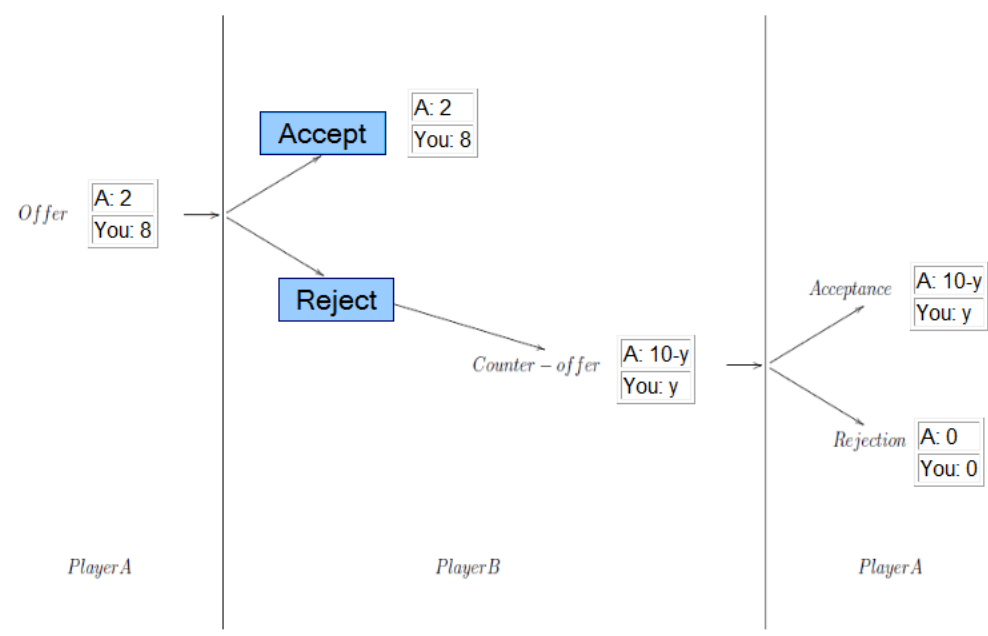




\section{Player B}

\section{Instructions - Part II}

We ask you now to guess some of the answers the other player gave or is about to give. You can earn additional money for your guesses if they are correct

\section{Player A -- Tasks}

If you were assigned the role of Player A, we ask you to guess if Player B will accept or reject your offer for all offers that you could have made. In case you think he will reject it, we also ask you to guess how much Player B will offer you in his counteroffer

\section{Player B -- Tasks}

If you were assigned the role of Player B, we ask you to make two guesses about answers Player A gave or is about to give:

1. We asked Player $A$ to guess your reaction to his proposed split of the $\$ 10$. We now ask you to guess how Player $\mathbf{A}$ thinks you would react for each of his potential partition propositions: If Player $A$ offered you $\$ X$, does he expect you to accept his offer? And if you think he does not expect you to accept it, how much does he think you will offer him in your

2. Suppose you rejected Player A's proposition. We ask you to guess how much you have to give at least to Player $\mathbf{A}$ in your counteroffer so that he still accepts it. This means that you would expect Player A to accept all of your counteroffers, in which you give him more than $\$ X$, and to reject all of your counteroffers, in which you give him less than $\$ X$. We ask you to make a guess about $\$ X$ for each of Player A's initial offers.

\section{Earnings}

You can earn additional money if your stated guesses match the actual answers given by the other player: You earn $\$ 0.50$ for every correct guess

- Player A: You receive an additional $\$ 0.50$ for each correct belief about Player B's acceptance decision. In case you correctly guess that Player B rejects your offer, you earn extra $\$ 0.50$ if your guess about Player B's counteroffer coincides with his actual offer

- Player B: You receive additional money if your guess about Player A's expectation of your reaction matches his actual expectation. Here you can earn $\$ 0.50$ for each correct guess on whether Player A expects you to accept his offer an case of a correctly expected rejection you receive $\$ 0.50$ for each correct guess about what he expects you to counteroffer Furthermore, you earn an additional $\$ 0.50$ for each correct guess about Player A's smallest accepted counteroffer. 
1. Suppose Player A's proposition was to keep $\$ X$ for himself and to offer you $\$ 10-X$. Suppose further that you guessed that Player A expects you to reject this proposition and to make a counteroffer, in which he gets \$Y. Assume Player A indeed thinks that you would reject such a proposition and that he guessed you would make a counteroffer, in which you offer him $\$ Z$

How much do you earn for your guess?

2. Suppose again Player A's proposition was to keep $\$ X$ for himself and to offer $\$ 10$-X to you and that he said he would reject all counteroffers below \$F. Suppose further that you guessed he would reject all of your counteroffers below \$G.

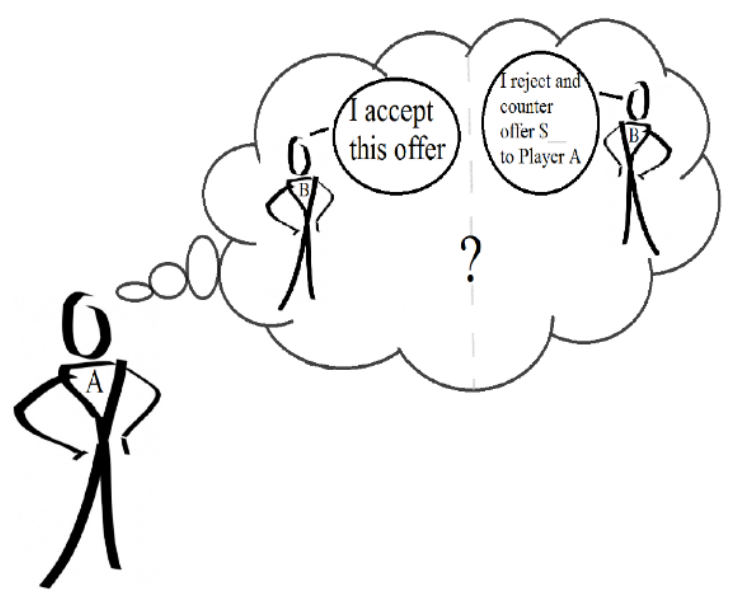

Please guess whether you think Player A expects you to accept or to reject his offer. In the following, you are asked to make this guess for each of his possible offers. In case you think Player A expects you to reject his offer, we will also ask you to guess how much he expects you to counteroffer him. 


\section{Player B}

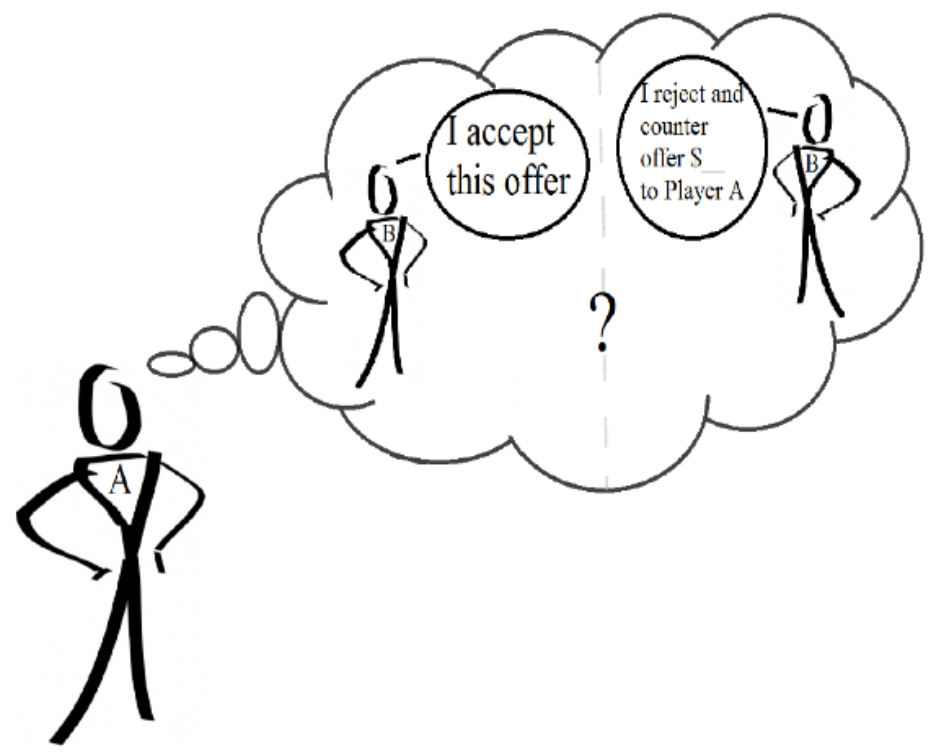

Suppose Player A's choice was to keep 3 for himself and to offer you 7 .

Do you think Player A expects you to accept or reject this offer?

Accept Reject 


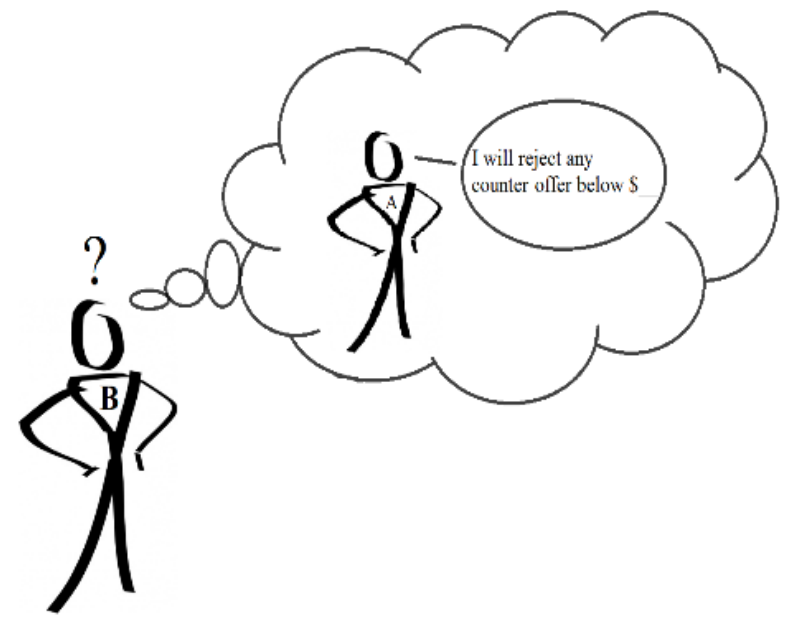

Suppose you rejected. Please guess which is the smallest counteroffer you could have made to Player A so that he would just accept it.

Given that Play er A proposed to keep 3 for him self, I think Player A would reject all of my counteroffers in which he gets less than $\$$

So, you think that Player A would accept all counteroffers above and equal to $\$ \_$and reject any of your counteroffers below $\$$ 


\section{Player B}

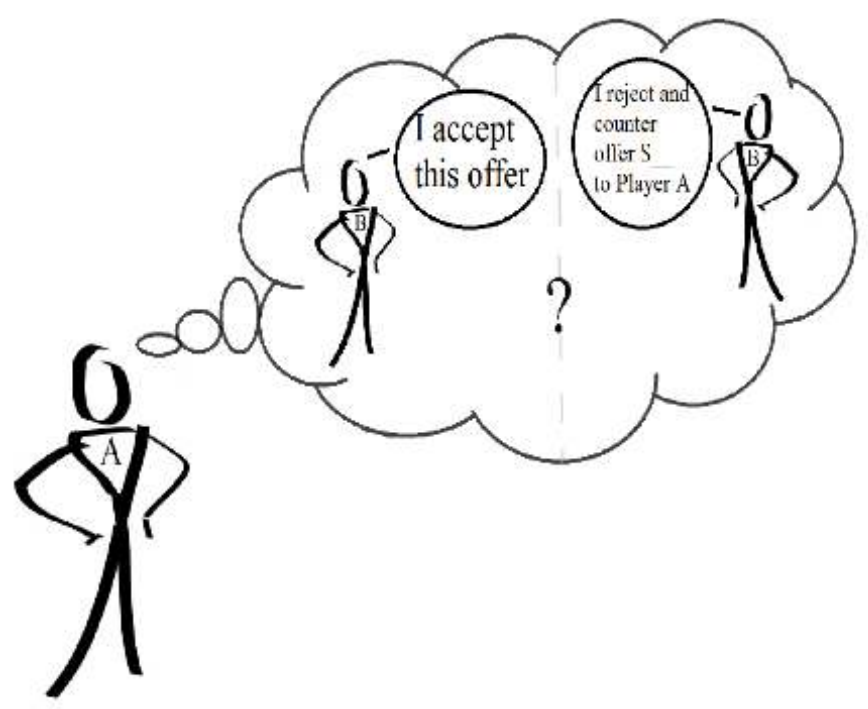

Suppose Player A's choice was to keep 3 for himself and to offeryou 7.

Do you think Player A expects you to accept or reject this offer?

\begin{tabular}{l|l|}
\hline Accept & Reject \\
\hline
\end{tabular} 


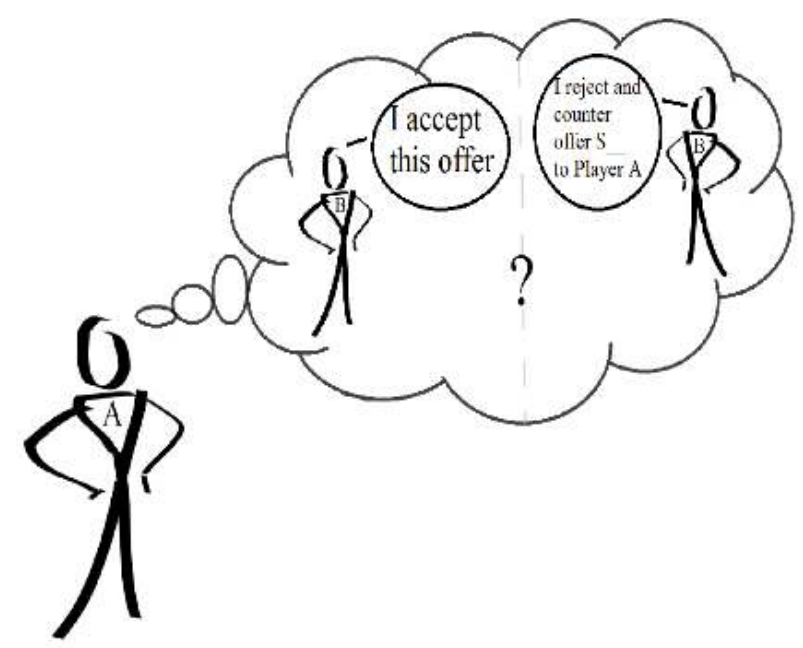

You have just said you believe Player A expects you to reject a proposition in which he keeps 3 for himself and gives 7 to you. How much do you think he expects you to counteroffer him?

I think Player A expects a counteroffer, in which he gets $\$$ from the $\$ 10$. 
Now, we will ask you a few general questions. Please answer truthfully, nobody will be able to attribute your answers to you as we will keep them completely anony mous.

\begin{tabular}{|l|l|l|l|}
\hline Your gender & \begin{tabular}{|l|l|}
\hline Your age \\
\hline How often have you participated in experiments?
\end{tabular} \\
\hline How many other participants in this experiment \\
(in this room) do you know personally?
\end{tabular}


C Instructions Questionnaire for obsevers 


\section{General Instructions}

\section{General Remarks}

Thank you for participating in this experiment on decision-making. During the experiment you and the other participants are asked to answer a series of questions. At the end you will receive a flat payment of $\$ 10$, which is independent of the answers you will give. Please, nevertheless, read the instructions carefully and answer the questions truthfully.

Please consider all expressions as gender neutral.

Please do not communicate with other participants. If you have any questions after we finish reading the instructions please raise your hand and an experimenter will approach you and answer your question in private.

\section{Your Role}

In this experiment, you are asked to take the role of an impartial Observer whose task is to make guesses and judgements concerning the behaviour of players in the game described below. It is a typical game that has been played out many times.

\section{Privacy}

This experiment is designed such that nobody, including the experimenters and the other participants, will ever be informed about the answers you or anyone else will give in the experiment. Neither your name nor your student ID will appear on any decision form. The only identifying label will be a number that is known only to you.. 


\section{Your Questionnaire}

Suppose Player A's initial proposition was to keep $\$ 3$ for himself and to offer $\$ 7$ to Player B.

1. Do you think Player A expects Player B to accept or to reject his proposition?

A expects $B$ to accept.

A expects $B$ to reject.

2. Now, suppose that $B$ rejects $A$ 's initial proposition to keep $\$ 8$ for himself. What do you think is the lowest counter-offer Player A would then accept from Player B? This means that you would expect such a Player A to accept all counter-offers, in which he receives more or equal than ...

$\begin{array}{ll}\$ 0 & \$ 6 \\ \$ 1 & \$ 7 \\ \$ 2 & \$ 8 \\ \$ 3 & \$ 9 \\ \$ 4 & \$ 10\end{array}$

$\ldots$ and to reject all counter-offers, in which he gets less than the amount.

3. How much do you think a Player A who makes such a proposition expects to earn at the end?

$\begin{array}{ll}\$ 0 & \$ 6 \\ \$ 1 & \$ 7 \\ \$ 2 & \$ 8 \\ \$ 3 & \$ 9 \\ \$ 4 & \$ 10\end{array}$

4. On a scale from 0 to 10 , how fair do you think Player A's proposition is?

\begin{tabular}{|c|c|c|c|c|c|c|c|c|c|c|}
\hline 0 - very unfair & 1 & 2 & 3 & 4 & 5 & 6 & 7 & 8 & 9 & 10 - very fair \\
\hline$\square$ & $\square$ & $\square$ & $\square$ & $\square$ & $\square$ & $\square$ & $\square$ & $\square$ & $\square$ & $\square$ \\
\hline
\end{tabular}

5. On a scale from 0 to 10 , how kind do you think Player A's proposition is?

\begin{tabular}{|c|c|c|c|c|c|c|c|c|c|c|}
\hline 0 - very unkind & 1 & 2 & 3 & 4 & 5 & 6 & 7 & 8 & 9 & 10 - very kind \\
\hline$\square$ & $\square$ & $\square$ & $\square$ & $\square$ & $\square$ & $\square$ & $\square$ & $\square$ & $\square$ & $\square$ \\
\hline
\end{tabular}


6. Why do you think Player A made a proposition, in which he keeps $\$ 8$ ? (You can cross more than one answer.)

He is tough / would reject low counter-offers.

He wants to appear tough / make Player A think that he would reject low counteroffers.

$\mathrm{He}$ is fair.

He is smart.

He wants to assure himself the larger part of the $\$ 10$.

$\mathrm{He}$ is kind.

$\mathrm{He}$ is selfish.

He is nasty.

He did not understand the game.

Other:

7. Receiving such an offer, in which you get $\$ 2$ of the $\$ 10$, how would you feel? (You can cross more than one answer.)

Fine.

Insulted.

Understanding.

Good.

Neutral.

Angry.

Happy.

Other:

8. After receiving such a proposal, in which you receive $\$ 2$ of the $\$ 10$, would you consider to make a counter-offer to $A$, which is so low that you find it likely to be rejected by $A$ ?

Yes.

No.

9. Suppose you were Player B and had the choice to end the game without an agreement (payoff of $\$ 0$ for both of you). After receiving such a proposal, in which you receive $\$ 2$ of the $\$ 10$, would you choose to end the game?

Yes.

No. 